\title{
LeChatelier Principle and the Effects of Trade Policy under Induced Innovation
}

\author{
Jean-Paul Chavas \\ Department of Agricultural and Applied Economics, University of Wisconsin, Madison, USA \\ Email: jchavas@wisc.edu
}

Received May 5, 2012; revised June 7, 2012; accepted July 6, 2012

\begin{abstract}
This paper explores the effects of trade policy under induced innovation in general equilibrium. The analysis considers the effects of discrete changes in tariffs and import quotas, allowing for heterogeneous technologies among firms. The interactions between induced innovation and the effects of trade policy give a set of "LeChatelier effects" comparing short run versus long run market equilibrium. We investigate how induced innovation can reduce the adverse effects of tariffs on trade, and influence the effects of quotas on corresponding quota rents. The analysis presents new LeChatelier results that apply globally, i.e. under any discrete change in trade policy.
\end{abstract}

Keywords: Trade Policy; Tariffs; Quotas; Induced Innovation; LeChatelier

\section{Introduction}

Globalization has stimulated much research on the effects of trade policy (including tariffs and quotas) on resource allocation and welfare. The relationships between trade and technology have also been the subject of much interest (e.g., [1]). Yet, technology can evolve in response to changes in market conditions. Hicks [2] proposed the idea of induced innovation, where changes in relative prices stimulate the adoption of technologies that increase (decrease) the use of inputs that are becoming cheaper (more expensive). And applied to the output side, induced innovation means that price changes induce the adoption of technologies that increase (decrease) the production of commodities exhibiting higher (lower) prices. This has stimulated much research on how technology can adapt to changing resource scarcity (e.g., [3-5]). When market prices influence technology, trade policy would also affect technology choices. Indeed, import tariffs and quotas on specific commodities increase their prices in domestic markets. And they influence the prices of all goods through market equilibrium effects. This suggests that induced innovation would stimulate the adoption of technologies in response to the changes in all prices affected by trade policy.

The interactions between technology choice and trade policy (and its effects on market prices) is relevant when the process of technology adoption is slow. This can happen when new technology is embodied in physical or human capital, as firms that just invested in capital do not have incentives to adopt an improved technology until their capital depreciates. Or this can happen when the adoption of a new technology involves learning cost. Firms facing lower learning cost are likely to be "early adopters" of a new technology, while other firms would be classified as "late adopters". Technology adoption being slow, this motivates a need to distinguish between short run and long run situations. This distinction is at the heart of "LeChatelier effects" investigated in this paper.

The LeChatelier principle reflects the basic intuition that restricting choices can lower the ability to make economic adjustments. It was first introduced in economics by Samuelson $([6,7])$, who proved that such results hold "locally", i.e. for small changes in the neighborhood of a point. Local LeChatelier effects have been examined in the context of trade by Neary [8] and Kreickemeier [9]. It is well known that local LeChatelier results do not necessarily hold globally, i.e. when facing discrete changes in economic conditions ([7,10,11]). It is also known that local LeChatelier results can hold globally under some restrictive assumptions. This raises the following questions. Is it possible to obtain general implications of the LeChatelier principle without imposing restrictive assumptions? And what are these implications in the context of trade policy? Our analysis answers these two questions in a positive way.

This paper investigates LeChatelier effects under induced innovation in the context of trade policy changes in general equilibrium. Our LeChatelier results apply globally to any discrete change in trade policy (including 
both tariffs and quotas). This is important for two reasons. First, actual policy changes typically take the form of large changes in policy instruments. Second, our "global LeChatelier results" are obtained without imposing restrictive assumptions (e.g., without assuming supermodularity). While we show how "local results" hold as a special case, obtaining global LeChatelier results is a key contribution of our analysis.

Capturing the economy-wide effects of trade policy under induced innovation requires a general equilibrium model. Following Dixit and Norman [12] and Luenberger [13], we rely on a dual general equilibrium model of trade. The presence of early adopters and late adopters requires considering that technology can vary among firms (e.g., exporting firms versus domestic firms). Our analysis allows for firm entry/exit and its general equilibrium effects. The model also considers an arbitrary number of commodities. This allows for differentiated products. In this context, the paper studies the effects of discrete changes in both tariffs and quotas. This is relevant as trade policy reform often means partial market liberalization that involves the joint effects of tariff and quotas. Considering discrete changes in trade policy expands on previous analyses of market liberalization that focused on small changes in policy instruments (e.g., [14-16]).

Our analysis studies market equilibrium under price and quantity distortions. This provides a basis for evaluating the efficiency gains/losses from any discrete change in trade policy. The analysis presents conditions under which a discrete policy change improves aggregate efficiency. It examines the interactions between induced innovation and the effects of trade policy. These interactions generate a set of "LeChatelier effects" comparing short run versus long run market equilibrium.

Three important results are obtained. First, we show that induced innovation tends to reduce the aggregate welfare loss generated by distortionary trade policy. It means that previous research that ignored induced innovation has overstated the adverse effects of trade policies. This result holds under very general conditions. To the extent that trade policy is motivated by rent seeking behavior (which redistributes welfare toward the "rent seekers"), this also means that induced innovation can tamper the efficiency losses from rent seeking behavior. Second, we examine how induced innovation can reduce the adverse effects of tariffs on trade, providing information on how technology choices can moderate the negative impact of restrictive trade policy on trade. Third, we study how induced innovation can influence the effects of quotas on corresponding quota rents. The analysis also examines the presence of interaction effects between quotas and tariffs. Importantly, our "global LeChatelier results" hold without imposing restrictive assumptions and apply globally, i.e. for any discrete change in trade policy.

The paper is organized as follows. Section 2 starts with a discussion of induced innovation at the firm level. Section 3 presents a dual general equilibrium model of an economy under trade policy distortions, including both tariffs and quotas. The model provides a basis for analyzing the efficiency gains/losses generated by a discrete change in trade policy. Section 4 introduces the role of induced innovation. It presents global LeChatelier results showing how induced innovation interacts with the effects of both tariff and quota policies. Section 5 discusses the economic implications for economics and welfare. While local LeChatelier results apply as a special case, our global analysis provides new insights in the economic analysis of trade policy. Finally, section 6 concludes.

\section{Preliminary: Induced Innovations at the Firm Level}

Consider an economy involving a set $K=\{1, \ldots, \mathrm{K}\}$ of goods produced by a set $\boldsymbol{M}=\{1, \ldots, \mathrm{M}\}$ of firms. Using the netput notation, the $\mathrm{j}$-th firm produces $\mathbf{y}_{\mathrm{j}}=\left(\mathrm{y}_{1 \mathrm{j}}, \ldots\right.$, $\left.\mathrm{y}_{\mathrm{Kj}}\right) \in \mathrm{Y}_{\mathrm{j}} \subset \mathfrak{R}^{\mathrm{K}}$, where $\mathrm{y}_{\mathrm{kj}}$ is the k-th output (k-th input if negative) of the $\mathrm{j}$-th firm, and $\mathrm{Y}_{\mathrm{j}}$ is the feasible set representing the technology available to the $\mathrm{j}$-th firm, $\mathrm{j} \in \boldsymbol{M}$. Assume that all firms are price takers and that the set $Y_{j}$ is bounded and convex, $\mathrm{j} \in \boldsymbol{M}$. Denote by $\mathbf{p}=\left(\mathrm{p}_{1}, \ldots, \mathrm{p}_{\mathrm{K}}\right)$ $\in \mathfrak{R}_{+}^{\mathrm{K}}$ the vector of prices for the $\mathrm{K}$ commodities. Then, the profit maximizing decisions of the $\mathrm{j}$-th firm facing prices $\mathbf{p}$ are given by ${ }^{1}$

$$
\pi_{\mathrm{j}}\left(\mathbf{p}, \mathrm{Y}_{\mathrm{j}}\right)=\mathbf{p}^{\mathrm{T}} \mathbf{y}_{\mathrm{j}}^{*}\left(\mathbf{p}, \mathrm{Y}_{\mathrm{j}}\right)=\max _{\mathbf{y}}\left\{\mathbf{p}^{\mathrm{T}} \mathbf{y}_{\mathrm{j}}: \mathbf{y}_{\mathrm{j}} \in \mathrm{Y}_{\mathrm{j}}\right\}
$$

where $\pi_{j}\left(\mathbf{p}, Y_{j}\right)$ is the indirect profit function, and $\mathbf{y}_{\mathrm{j}}{ }^{*}(\mathbf{p}$, $\left.Y_{j}\right)$ is the corresponding profit maximizing decision, $j \in$ M.

As discussed in the introduction, following Hicks [2], induced innovation reflects that relative prices can help guide the innovation process (e.g., [3-5]). Induced innovation stimulates the adoption of technologies that increase (decrease) the use of inputs that are becoming cheaper (more expensive). And applied to the output side, induced innovation suggests that price changes stimulate the adoption of technologies that increase (decrease) the production of commodities exhibiting higher (lower) prices. To see that, consider the case where the j-th firm has the option to choose between $\mathrm{T}$ technologies: $\mathrm{Y}_{\mathrm{j}}{ }^{1}, \ldots$, $Y_{j}{ }^{T}$. Denote the set of technology indexes by $\mathbf{I}=\{1, \ldots$, $\mathrm{T}$ \}. Then, from (1) and for given prices $\mathbf{p}$, the incremental profit obtained by $\mathrm{j}$-th firm switching from technology $\mathrm{T}_{\mathrm{j}}^{\mathrm{i}}$ to $\mathrm{T}_{\mathrm{j}}^{\mathrm{i}{ }^{\prime}}$ is: $\Delta_{\mathrm{jii}}{ }^{\prime} \equiv \pi_{\mathrm{j}}\left(\mathbf{p}, \mathrm{Y}_{\mathrm{j}}^{\mathrm{i}}\right)-\pi_{\mathrm{j}}\left(\mathbf{p}, \mathrm{Y}_{\mathrm{j}}^{\mathrm{i}}{ }^{\mathrm{\prime}}\right)$, for $\mathrm{i}, \mathrm{i}^{\prime} \in$ I.

${ }^{1}$ In our notation, all vectors are treated as column vectors, and the superscript " $T$ " denotes the transpose. 
Technology adoption is typically slow. As discussed in the introduction, this can happen for at least two reasons: when technology is embodied in physical or human capital that depreciates slowly; and when learning about a new technology is costly. To capture the dynamics of technology adoption, for the $\mathrm{j}$-th firm, denote the cost of switching from technology $i$ to $i$ ' after $t$ periods by $\mathrm{C}_{\mathrm{j}}(\mathrm{i}, \mathrm{i}$, $t) \geq 0$. For the $j$-th profit maximizing firm, the decision to switch technology from i to i' after t periods would depend on the present value of incremental profit $\Delta_{\mathrm{jii}}$ minus switching cost $\mathrm{C}_{\mathrm{j}}(\mathrm{i}, \mathrm{i}, \mathrm{t}, \mathrm{t})$. We make the following assumption:$$
0 .
$$$$
\text { Assumption As1: For any i, i' } \in \mathrm{I}, \lim _{\mathrm{t} \rightarrow \infty} \mathrm{C}_{\mathrm{j}}\left(\mathrm{i}, \mathrm{i}^{\prime}, \mathrm{t}\right)=
$$

Assumption As1 states that, over time, the cost of switching between any two technologies declines toward zero. Assume for the moment that $\mathbf{p}$ is constant. In the short run, technology adoption decisions can be complex. The firm would decide to switch from i to i' when the incremental profit $\Delta_{\mathrm{jii}}$, is large enough to dominate the switching $\operatorname{cost} \mathrm{C}_{\mathrm{j}}(\mathrm{i}, \mathrm{i}, \mathrm{t}, \mathrm{t})$. But a positive incremental profit is not sufficient: the presence of large switching cost could induce the firm to stay with technology $i$ even if $\Delta_{\mathrm{jii}}>0$.

Under Assumption As1, technology adoption decisions are simpler in the long run (when $t \rightarrow \infty$ ). Under As1 and profit maximization, the long run technology decision made by the $\mathrm{j}$-th firm is as follows:

$$
\mathrm{Y}_{\mathrm{j}}^{*}(\mathbf{p})=\max _{\mathrm{Y}}\left\{\pi_{\mathrm{j}}\left(\mathbf{p}, \mathrm{Y}_{\mathrm{j}}^{\mathrm{i}}\right): \mathrm{i} \in \mathbf{I}\right\}
$$

This shows that, in the long run, technology choice $Y_{j}^{*}(\mathbf{p})$ in general depends of prices $\mathbf{p}$. This is consistent with the induced innovation hypothesis.

Now, consider a change in prices from $\mathbf{p}$ to $\mathbf{p}^{\prime} \in \mathfrak{R}_{+}^{\mathrm{K}}$. It follows that, for the $\mathrm{j}$-th firm in the long run, the profit maximizing technology would change from $Y_{j}^{*}(\mathbf{p})$ to $Y_{j}^{*}\left(\mathbf{p}^{\prime}\right)$. This illustrates that induced innovation involves the interactions between technology choice and market prices. These interactions become relevant when the process of technology adoption is slow. This suggests the need to distinguish between short run and long run situations. We define the short run (S) as a situation where a firm does not have enough time to change their previous technology. And under As1, we define the long run (L) as corresponding to situations where a firm has had enough time to adopt profitable technologies. Implications of this distinction for economic analysis of trade policy are investigated in sections 4 and 5 below.

In the long run for the $\mathrm{j}$-th firm, note that a price change from $\mathbf{p}$ to $\mathbf{p}^{\prime}$ induces netput changes from $\mathbf{y}_{\mathbf{j}}^{*}(\mathbf{p}$, $\left.\mathrm{Y}_{\mathrm{j}}^{*}(\mathbf{p})\right)$ to $\mathbf{y}_{\mathrm{j}}^{*}\left(\mathbf{p}^{\prime}, \mathrm{Y}_{\mathrm{j}}^{*}\left(\mathbf{p}^{\prime}\right), \mathrm{j} \in \boldsymbol{M}\right.$. This includes two effects: the direct price effect and the indirect effect of induced innovation (from $Y_{j}^{*}(\mathbf{p})$ to $Y_{j}^{*}\left(\mathbf{p}^{\prime}\right)$ ). While analyzing each effect is straightforward, analyzing them jointly is more challenging. Two aspects of these adjustments are worth stressing. First, our analysis allows for some firms in $\boldsymbol{M}$ to be inactive. Indeed, the $\mathrm{j}$-th firm would be completely inactive under prices $\mathbf{p}$ and technology $T_{j}$ if $\mathbf{y}_{j}{ }^{*}\left(\mathbf{p}, Y_{j}\right)=0$ in (1). Or it could be inactive in some markets (when $\mathrm{y}_{\mathrm{kj}}{ }^{*}\left(\mathbf{p}, \mathrm{Y}_{\mathrm{j}}\right)=0$ for some $\left.\mathrm{k} \in \boldsymbol{K}\right)$ while being active in others (when $\mathrm{y}_{\mathrm{k}}{ }^{*}{ }^{*}\left(\mathbf{p}, \mathrm{Y}_{\mathrm{j}}\right) \neq 0$ for some $\mathrm{k}^{\prime} \in \boldsymbol{K}-\mathrm{k}$ ). As prices change and technology changes, it follows that the number of inactive firms in any particular market would also change. It means that the changes from $\mathbf{y}_{\mathbf{j}}^{*}\left(\mathbf{p}, Y_{j}^{*}(\mathbf{p})\right)$ to $\mathbf{y}_{\mathrm{j}}^{*}\left(\mathbf{p}^{\prime}, \mathrm{Y}_{\mathrm{j}}^{*}\left(\mathbf{p}^{\prime}\right), \mathrm{j} \in M\right.$, can capture entry/exit processes of firms in any of the $\mathrm{K}$ markets. Importantly, both price changes (from $\mathbf{p}$ to $\mathbf{p}$ ') and induced technological innovation (from $Y_{j}^{*}(\mathbf{p})$ to $Y_{j}^{*}\left(\mathbf{p}^{\prime}\right)$ ) can affect entry-exit in any market.

Second, our analysis allows for technology to vary across firms as well as over time. The heterogeneity of technology across firms is captured by defining a feasible set that is firm-specific ( $Y_{j}$ for the $j$-th firm). This can reflect the role of agroclimatic and location-specific effects. And the technological options available in the process of induced innovation are also firm-specific $\left(\left(Y_{j}^{1}, \ldots, Y_{j}^{T}\right)\right.$ for the $j$-th firm. This can capture heterogeneity in human capital across firms. Note that the role of entry-exit and heterogeneous technology has been identified in the literature (e.g., [17]). The above discussion indicates that our analysis does capture such effects.

So far, our discussion has been at the firm level. This provides a building block for the rest of the paper. But it suffers from a significant drawback: it does not explain what causes price changes. To resolve this issue, we need to present the analysis at the aggregate level, where prices are the outcome of market equilibrium. As discussed in the introduction, our focus is on the analysis of trade policy. It means that we need to evaluate the evolution of prices as the outcome of trade policy reforms. This is the topic of the next sections.

\section{Trade under Policy Distortions}

As discussed in Section 2, the economy involves a set $\boldsymbol{K}$ $=\{1, \ldots, \mathrm{K}\}$ of goods produced by a set $\boldsymbol{M}=\{1, \ldots, \mathrm{M}\}$ of firms. The j-th firm produces netputs $\mathbf{y}_{\mathrm{j}}=\left(\mathrm{y}_{1 \mathrm{j}}, \ldots, \mathrm{y}_{\mathrm{Kj}}\right)$ $\in Y_{j} \subset \mathfrak{R}^{K}$, where $Y_{j}$ is the feasible set representing the technology available to the $\mathrm{j}$-th firm, $\mathrm{j} \in \boldsymbol{M}$. The $\mathrm{K}$ goods are consumed by a set $N=\{1, \ldots, N\}$ of households. The $\mathrm{i}$-th household has initial endowment $\mathbf{w}_{\mathrm{i}}=\left(\mathrm{w}_{1 \mathrm{i}}, \ldots, \mathrm{w}_{\mathrm{Ki}}\right)$, consumes $\mathbf{x}_{\mathrm{i}}=\left(\mathrm{x}_{1 \mathrm{i}}, \ldots, \mathrm{x}_{\mathrm{Ki}}\right) \in \mathfrak{R}_{+}^{\mathrm{K}}$ and has preferences represented by the utility function $\mathrm{u}_{\mathrm{i}}\left(\mathbf{x}_{\mathrm{i}}\right), \mathrm{i} \in \boldsymbol{N}$. Let $\mathbf{x} \equiv$ $\left(\mathbf{x}_{1}, \ldots, \mathbf{x}_{\mathrm{N}}\right), \mathbf{y} \equiv\left(\mathbf{y}_{1}, \ldots, \mathbf{y}_{\mathrm{M}}\right)$, and $\mathrm{Y} \equiv \mathrm{Y}_{1} \times \ldots \times \mathrm{Y}_{\mathrm{M}}$. As noted above, this allows for heterogeneous technologies among firms. An allocation $(\mathbf{x}, \mathbf{y})$ is feasible if it satisfies $\mathbf{x} \in \mathfrak{R}_{+}^{\mathrm{NK}}, \mathbf{y} \in \mathrm{Y}$, and

$$
\sum_{\mathrm{i} \in N} \mathbf{x}_{\mathrm{i}} \leq \sum_{\mathrm{i} \in N} \mathbf{w}_{\mathrm{i}}+\sum_{\mathrm{j} \in \boldsymbol{M}} \mathbf{y}_{\mathrm{j}}
$$


where Equation (3) is the commodity balance equation stating that aggregate consumption cannot exceed the aggregate supply of each good.

Throughout the paper, we assume that the set $\mathrm{Y}$ is closed, bounded and convex, ${ }^{2}$ and that the set $\left\{\sum_{\mathrm{j} \in M} \mathrm{Y}_{\mathrm{j}}+\right.$ $\left.\sum_{\mathrm{i} \in N} \mathbf{w}_{\mathrm{i}}\right\} \cap \mathfrak{R}_{+}^{\mathrm{K}}$ has a non-empty interior. And we assume that the utility function $\mathrm{u}_{\mathrm{i}}\left(\mathbf{x}_{\mathrm{i}}\right)$ is continuous, nonsatiated and quasi-concave on $\Re_{+}^{\mathrm{K}}, \mathrm{i} \in N$.

Under prices $\mathbf{p} \in \mathfrak{R}_{+}^{\mathrm{K}}$, let production decisions be made by profit maximizing firms according to Equation (1). And let

$$
\begin{aligned}
\mathrm{e}_{\mathrm{i}}\left(\mathbf{p}, \mathrm{U}_{\mathrm{i}}\right) & =\mathbf{p}^{\mathrm{T}} \mathbf{x}_{\mathrm{i}}^{*}\left(\mathbf{p}, \mathrm{U}_{\mathrm{i}}\right) \\
& =\operatorname{Min}_{\mathbf{x}}\left\{\mathbf{p}^{\mathrm{T}} \mathbf{x}_{\mathrm{i}}: \mathrm{u}\left(\mathbf{x}_{\mathrm{i}}\right) \geq \mathrm{U}_{\mathrm{i}}, \mathbf{x}_{\mathrm{i}} \in \mathfrak{R}_{+}^{\mathrm{K}}\right\}
\end{aligned}
$$

be the expenditure function for the i-th household, where $\mathbf{x}_{i}^{*}\left(\mathbf{p}, \mathrm{U}_{\mathrm{i}}\right)$ is the corresponding Hicksian demand, $\mathrm{i} \in N$.

To analyze trade policy, consider that the economy includes two regions, A and B. Region A has a trade policy involving a mix of tariffs and quotas on imported goods. Let with $\mathbf{t}=\left(\mathrm{t}_{1}, \ldots, \mathrm{t}_{\mathrm{K}}\right)$ be the tariffs on imported goods, where $t_{k}$ is the import tariff (or export subsidy if $t_{k}<0$ ) on the k-th product. And let $\mathbf{q}=\left(\mathrm{q}_{1}, \ldots, \mathrm{q}_{\mathrm{K}}\right) \in \mathfrak{R}_{+}^{\mathrm{K}}$ denote the import quotas, where $\mathrm{q}_{\mathrm{k}}$ the import quota on the $\mathrm{k}$-th product. While we allow for both tariffs and quotas, our analysis considers situations where each type of policy instrument applies to different goods. It means that import tariffs may be imposed on some goods while import quotas are imposed on other goods. In this context, $t_{k}=0$ when the k-th good is not subject to a tariff (or tax), while $\mathrm{q}_{\mathrm{k}}=\infty$ when the $\mathrm{k}$-th good is not subject to an import quota, k $\in \boldsymbol{K}$. Let $\boldsymbol{N}=\left(\boldsymbol{N}_{\mathrm{A}}, \boldsymbol{N}_{\mathrm{B}}\right)$ and $\boldsymbol{M}=\left(\boldsymbol{M}_{\mathrm{A}}, \boldsymbol{M}_{\mathrm{B}}\right)$ where $N_{\mathrm{r}}$ is the set of households in region r, and $\boldsymbol{M}_{\mathrm{r}}$ is the set of firms in region $r, r=A, B$. The tariffs $\mathbf{t}$ apply to net imports into region $\mathrm{A}: \mathbf{m}_{\mathrm{A}} \equiv \sum_{\mathrm{i} \in N \mathrm{~A}} \mathbf{x}_{\mathrm{i}}-\sum_{\mathrm{i} \in N \mathrm{~A}} \mathbf{w}_{\mathrm{i}}-$ $\sum_{\mathrm{j} \in M \mathrm{~A}} \mathbf{y}_{\mathbf{j}}$. Similarly, the quotas $\mathbf{q}$ impose the following trade restricttion: ${ }^{3}$

$$
\sum_{\mathrm{i} \in N \mathrm{~A}} \mathbf{x}_{\mathrm{i}}-\sum_{\mathrm{i} \in N \mathrm{~A}} \mathbf{w}_{\mathrm{i}}-\sum_{\mathrm{j} \in \boldsymbol{M A}} \mathbf{y}_{\mathrm{j}} \leq \mathbf{q}
$$

We want to analyze the implications of trade policy represented by the policy instruments $(\mathbf{t}, \mathbf{q})$. Let $\lambda=$ $\left(\lambda_{1}, \ldots, \lambda_{\mathrm{K}}\right) \in \mathfrak{R}_{+}^{\mathrm{K}}$ denote the quota rents associated with the quota restrictions (5). ${ }^{4}$ Below, following Dixit and Norman [12] and Luenberger [13], we present a dual general equilibrium model of trade and use it to examine the effects of trade policy $(\mathbf{t}, \mathbf{q})$ on prices $\mathbf{p}$, on the quota rents $\lambda$, on trade, and on welfare. As investigated in previous literature (e.g., [8,18-22]), the dual approach to

\footnotetext{
${ }^{2}$ Note that assuming that $\mathrm{Y} \equiv \mathrm{Y}_{1} \times \ldots \times \mathrm{Y}_{\mathrm{M}}$ is a convex set rules out technologies exhibiting increasing returns to scale. Yet, it allows each firm to be active (if its productivity is "relatively high") or inactive (if its productivity is "low").

${ }^{3}$ Note that the trade quotas $\mathbf{q}$ place an upper-bound on imports in region A. When $\mathbf{q} \geq 0$, such quotas impose no restriction on exports from region A.

${ }^{4}$ The quota rent $\lambda_{\mathrm{k}}$ would be positive (zero) when the corresponding quota restriction is binding (not binding) for the $\mathrm{k}$-th commodity, $\mathrm{k} \in$ K.
}

trade policy analysis relies on the profit function $\pi_{\mathrm{j}}\left(\mathbf{p}, \mathrm{Y}_{\mathrm{j}}\right)$ in Equation (1) and the expenditure function $\mathrm{e}_{\mathrm{i}}\left(\mathbf{p}, \mathrm{U}_{\mathrm{i}}\right)$ in Equation (4).

Let $\mathbf{g} \in \mathfrak{R}_{+}^{\mathrm{K}}$ be some reference bundle satisfying $\mathbf{g} \neq$ 0. Under the price normalization rule $\mathbf{p}^{\mathrm{T}} \mathbf{g}=1$, consider the following minimization problem

$$
\begin{aligned}
& \mathrm{V}(\mathbf{U}, \mathbf{t}, \mathbf{q}, \mathrm{Y}) \\
& =\min _{\mathbf{p}, \lambda}\left\{(\mathbf{p}+\lambda+\mathbf{t})^{\mathrm{T}} \sum_{\mathrm{i} \in N \mathrm{~A}} \mathbf{w}_{\mathrm{i}}\right. \\
& \quad+\mathbf{p}^{\mathrm{T}} \sum_{\mathrm{i} \in N \mathrm{~B}} \mathbf{w}_{\mathrm{i}}+\lambda^{\mathrm{T}} \mathbf{q} \\
& \quad+\sum_{\mathrm{j} \in M \mathrm{~A}} \pi_{\mathrm{j}}\left(\mathbf{p}+\lambda+\mathbf{\lambda}, \mathrm{Y}_{\mathrm{j}}\right)+\sum_{\mathrm{j} \in M \mathrm{~B}} \pi_{\mathrm{j}}\left(\mathbf{p}, \mathrm{Y}_{\mathrm{j}}\right) \\
& \quad-\sum_{\mathrm{i} \in N \mathrm{~A}} \mathrm{e}_{\mathrm{i}}\left(\mathbf{p}+\lambda+\mathbf{p}, \mathrm{U}_{\mathrm{i}}\right)-\sum_{\mathrm{i} \in N \mathrm{~B}} \mathrm{e}_{\mathrm{i}}\left(\mathbf{p}, \mathrm{U}_{\mathrm{i}}\right) \\
& \left.\quad \quad \quad \mathbf{p}^{\mathrm{T}} \mathbf{g}=1, \mathbf{p} \in \mathfrak{R}_{+}^{\mathrm{K}}, \boldsymbol{\lambda} \in \mathfrak{R}_{+}^{\mathrm{K}}\right\},
\end{aligned}
$$

which has solution $\mathbf{p}^{*}(\mathbf{U}, \mathbf{t}, \mathbf{q}, \mathrm{Y})$ and $\lambda^{*}(\mathbf{U}, \mathbf{t}, \mathbf{q}, \mathrm{Y})$, where $\mathbf{U}=\left(\mathrm{U}_{1}, \ldots, \mathrm{U}_{\mathrm{N}}\right)$. Let

$$
\begin{aligned}
\mathrm{W}(\mathbf{U}, \mathbf{t}, \mathbf{q}, \mathrm{Y}) & \\
& \equiv \mathrm{V}(\mathbf{U}, \mathbf{t}, \mathbf{q}, \mathrm{Y})-\mathbf{t}^{\mathrm{T}} \mathbf{m}_{\mathrm{A}}{ }^{*}(\mathbf{U}, \mathbf{t}, \mathbf{q}, \mathrm{Y}),
\end{aligned}
$$

where $\mathbf{m}_{\mathrm{A}}{ }^{*}(\mathbf{U}, \mathbf{t}, \mathbf{q}, Y)$ is the aggregate demand for net imports into region A defined as

$$
\begin{aligned}
\mathbf{m}_{\mathrm{A}}{ }^{*} & (\mathbf{U}, \mathbf{t}, \mathbf{q}, \mathrm{Y}) \equiv \sum_{\mathrm{i} \in N \mathrm{~A}} \mathbf{x}_{\mathrm{i}}{ }^{*}\left(\mathbf{p}^{*}(\mathbf{U}, \mathbf{t}, \mathbf{q}, \mathrm{Y})\right. \\
& \left.+\lambda^{*}(\mathbf{U}, \mathbf{t}, \mathbf{q}, \mathrm{Y})+\mathbf{t}, \mathrm{U}_{\mathrm{i}}\right) \\
& -\sum_{\mathrm{i} \in N \mathrm{~A}} \mathbf{w}_{\mathrm{i}}-\sum_{\mathrm{j} \in M \mathrm{~A}} \mathbf{y}_{\mathrm{j}}^{*}\left(\mathbf{p}^{*}(\mathbf{U}, \mathbf{t}, \mathbf{q}, \mathrm{Y})\right. \\
& \left.+\lambda^{*}(\mathbf{U}, \mathbf{t}, \mathbf{q}, \mathrm{Y})+\mathbf{t}, \mathrm{Y}_{\mathrm{j}}\right) .
\end{aligned}
$$

It is clear that $\mathrm{V}(\mathbf{U}, \mathbf{t}, \mathbf{q}, \mathrm{Y})$ in Equation (6) and $\mathrm{W}(\mathbf{U}, \mathbf{t}$, q, Y) in Equation (7) involve monetary measures. The function $\mathrm{W}(\mathbf{U}, \mathbf{t}, \mathbf{q}, \mathrm{Y})$ in Equation (7) will play a key role in our analysis. As discussed below, it is a welfare indicator that will provide a basis to evaluate the economic and welfare effects of trade policy. As a starting point, two key results are stated next (see the proof in the Appendix).

Lemma 1: Let $\mathbf{U} \in\left\{\mathbf{U}^{\prime}: \mathrm{W}\left(\mathbf{U}^{\prime}, \mathbf{t}, \mathbf{q}, \mathrm{Y}\right)=0\right\}$. Then, under trade policy $(\mathbf{t}, \lambda)$,

1) $\mathbf{p}^{*}(\mathbf{U}, \mathbf{t}, \mathbf{q}, Y)$ and $\lambda^{*}(\mathbf{U}, \mathbf{t}, \mathbf{q}, Y)$ in Equation (6) are market equilibrium prices and quota rents, respectively;

2) $\mathrm{W}(\mathbf{U}, \mathbf{t}, \mathbf{q}, Y)$ in Equation (7) is a monetary measure of aggregate benefit, $\mathrm{W}(\mathbf{U}, \mathbf{t}, \mathbf{q}, \mathrm{Y})$ being non-increasing in $\mathbf{U}$.

Lemma 1 includes as a special case competitive markets in the absence of trade policy (when $\mathbf{t}=0$ and $\mathbf{q}=\infty$, i.e. when there is no tariff and quotas are non-binding). Then, $\mathrm{W}(\mathbf{U}, 0, \infty, \mathrm{Y})$ is Allais' distributable surplus under perfect competition $([23,24]) . \mathrm{W}(\mathbf{U}, 0, \infty, \mathrm{Y})$ being non-increasing in $\mathbf{U}$ reflects that reaching higher utilities is typically possible only with a redistribution of the aggregate surplus $\mathrm{W}$, i.e. a reduction in $\mathrm{W}$. When $\mathbf{t}=0$ and $\mathbf{q}=\infty$, and following Luenberger ([13,25]), Equation (6) defines a "minimal allocation"; and Equation (6) along with $\mathbf{U} \in\{\mathbf{U}$ ': $\mathrm{W}(\mathbf{U}$ ', $0, \infty, \mathrm{Y})=0\}$ define a "zerominimal allocation", i.e. a minimal allocation where all surplus has been redistributed to consumers. Zero-minimality, competitive equilibrium and Pareto efficiency are closely related concepts (e.g., $[13,25])$. It means that 
$\mathbf{p}^{*}(\mathbf{U}, 0, \infty, \mathbf{Y})$ are the competitive prices supporting a Pareto efficient allocation. In addition, the set $\left\{\mathbf{U}^{\prime}: \mathrm{W}\left(\mathbf{U}^{\prime}\right.\right.$, $0, \infty, Y)=0\}$ defines the Pareto utility frontier, i.e. the set of consumer utilities that can be reached under efficient allocations.

Thus, Equations (6) and (7) along with $\mathbf{U} \in\left\{\mathbf{U}^{\prime}\right.$ : $\left.\mathrm{W}\left(\mathbf{U}^{\prime}, \mathbf{t}, \mathbf{q}, \mathrm{Y}\right)=0\right\}$ provide a generalized representation of a zero-minimal allocation under trade policy $(\mathbf{t}, \mathbf{q})$. First, Equation (6) can be interpreted as a "distorted minimal allocation" under policy $(\mathbf{t}, \mathbf{q})$, with $\mathbf{p}^{*}(\mathbf{U}, \mathbf{t}, \mathbf{q}$, $\mathrm{Y})$ and $\lambda^{*}(\mathbf{U}, \mathbf{t}, \mathbf{q}, \mathrm{Y})$ as the corresponding market equilibrium prices and quota rents, respectively. Second, $\mathrm{W}(\mathbf{U}, \mathbf{t}, \mathbf{q}, \mathrm{Y})$ in (7) is a measure of aggregate benefit obtained under policy $(\mathbf{t}, \lambda)$. Note that the term $\left[\mathbf{t}^{\mathrm{T}} \mathbf{m}_{\mathrm{A}}{ }^{*}(\mathbf{U}\right.$, $\mathbf{t}, \mathbf{q}, \mathrm{Y})$ ] in Equation (7) represents the aggregate revenue generated by the tariffs $\mathbf{t}$. It means that $\mathrm{V}(\mathbf{U}, \mathbf{t}, \mathbf{q}, \mathrm{Y})$ in Equation (6) can be interpreted as a measure of aggregate benefit before tariff revenues are redistributed, and that $\mathrm{W}(\mathbf{U}, \mathbf{t}, \mathbf{q}, \mathrm{Y})$ in Equation (7) is a measure of aggregate benefit after tariff revenues are redistributed.

Third, after choosing $\mathbf{U}$ to satisfy $\mathrm{W}(\mathbf{U}, \mathbf{t}, \mathbf{q}, \mathrm{Y})=0$, Equations (6) and (7) characterize a "distorted zerominimal allocation" under policy $(\mathbf{t}, \mathbf{q})$. They also represent a "distorted market equilibrium" under policy $(\mathbf{t}, \mathbf{q})$. The introduction of trade policy in Equation (6) has two important effects. First, while $\mathbf{p}$ denotes prices in region $\mathrm{B}$, producers and consumers in region $\mathrm{A}$ now face prices $(\mathbf{p}+\lambda+\mathbf{t})$. When positive, this means that both import tariffs $\mathbf{t}$ and quota rents $\lambda$ contribute to increasing prices in region $\mathrm{A}$, with $(\lambda+\mathbf{t})$ denoting price wedges between the two regions. Note that the import tariffs $\mathbf{t}$ have direct effects on agents in region A: they affect aggregate profit $\sum_{\mathrm{j} \in M \mathrm{~A}} \pi_{\mathrm{j}}\left(\mathbf{p}+\lambda+\mathbf{t}, \mathrm{Y}_{\mathrm{j}}\right)$ as well as aggregate expenditure $\sum_{\mathrm{i} \in N \mathrm{~A}} \mathrm{e}_{\mathrm{i}}\left(\mathbf{p}+\lambda+\mathbf{t}, \mathrm{U}_{\mathrm{i}}\right)$ in region $\mathrm{A}$. When applied to net imports into region $\mathrm{A}, \mathbf{m}_{\mathrm{A}}$, the import tariffs $\mathbf{t}$ generate tariff revenue $\left[\mathbf{t}^{\mathrm{T}} \mathbf{m}_{\mathrm{A}}\right]$. As noted above, this tariff revenue gets redistributed to consumers, as captured by the subtraction of $\left[\mathbf{t}^{\mathrm{T}} \mathbf{m}_{\mathrm{A}}\right]$ in the evaluation of aggregate benefit $\mathrm{W}(\mathbf{U}, \mathbf{t}, \mathbf{q}, \mathrm{Y})$ in Equation (7). In general, tariffs affect efficiency (as discussed below) as well as the distribution of welfare (depending on how tariff revenues are redistributed). Second, the term $\lambda^{\mathrm{T}} \mathbf{q}$ in Equation (6) measures the aggregate quota rent generating income that is eventually captured by some agents. This quota rent affects both efficiency (as discussed below) and the distribution of welfare (depending on who captures it).

We know that $\left\{\mathbf{U}^{\prime}: \mathrm{W}\left(\mathbf{U}^{\prime}, 0, \infty, \mathrm{Y}\right)=0\right\}$ defines the Pareto utility frontier in the absence of trade policy. In an economy distorted by trade policy, choosing $\mathbf{U}$ to satisfy $\mathrm{W}(\mathbf{U}, \mathbf{t}, \mathbf{q}, \mathrm{Y})=0$ means that $\left\{\mathbf{U}^{\prime}: \mathrm{W}\left(\mathbf{U}^{\prime}, \mathbf{t}, \mathbf{q}, \mathrm{Y}\right)=0\right\}$ identifies the utility frontier under policy $(\mathbf{t}, \mathbf{q})$. In other words, $\left\{\mathbf{U}^{\prime}: \mathrm{W}\left(\mathbf{U}^{\prime}, \mathbf{t}, \mathbf{q}, \mathbf{Y}\right)=0\right\}$ is the set of consumer utilities that can be reached under distortionary trade policy. Thus, given $\mathbf{U} \in\left\{\mathbf{U}^{\prime}: \mathrm{W}\left(\mathbf{U}^{\prime}, \mathbf{t}, \mathbf{q}, \mathbf{Y}\right)=0\right\}$, the dis- torted zero-minimal allocation defined in Equations (6)(7) identifies $\mathbf{p}^{*}(\mathbf{U}, \mathbf{t}, \mathbf{q}, Y)$ as the market equilibrium prices in region $\mathrm{B}, \lambda^{*}(\mathbf{U}, \mathbf{t}, \mathbf{q}, \mathrm{Y})$ as the market equilibrium quota rents, and $\left[\mathbf{p}^{*}(\mathbf{U}, \mathbf{t}, \mathbf{q}, \mathrm{Y})+\lambda^{*}(\mathbf{U}, \mathbf{t}, \mathbf{q}, \mathrm{Y})+\mathbf{t}\right]$ as the market equilibrium prices in region $\mathrm{A}$.

Interpreting $\mathrm{W}(\mathbf{U}, \mathbf{t}, \mathbf{q}, \mathrm{Y})$ in Equation (7) as a measure of aggregate benefit under policy instruments $(\mathbf{t}, \mathbf{q})$, we will make use of $\mathrm{W}(\mathbf{U}, \mathbf{t}, \mathbf{q}, \mathrm{Y})$ to evaluate the aggregate welfare effects of trade policy. This includes the efficiency effects of quotas $\mathbf{q}$ (and associated quotas rents $\lambda$ ) and tariffs $\mathbf{t}$ (and associated tariff revenue). With $\{\mathbf{U}$ : $\mathrm{W}(\mathbf{U}, \mathbf{t}, \mathbf{q}, \mathrm{Y})=0\}$ representing the utility frontier under trade policy $(\mathbf{t}, \mathbf{q})$, the shift in the utility frontier associated with a policy change from $(\mathbf{t}, \mathbf{q})$ to $\left(\mathbf{t}^{\prime}, \mathbf{q}^{\prime}\right)$ can be measured by the associated change in aggregate benefit: $\Delta \mathrm{W} \equiv \mathrm{W}\left(\mathbf{U}, \mathbf{t}^{\prime} \mathbf{q}^{\prime}, \mathrm{Y}\right)-\mathrm{W}(\mathbf{U}, \mathbf{t}, \mathbf{q}, \mathrm{Y})$, a money-metric measure of aggregate welfare impact. For a given $\mathbf{U}$, finding $\Delta \mathrm{W}<0$ means an inward shift in the utility frontier, identifying a Pareto inferior move. And finding $\Delta \mathrm{W}$ $>0$ means an outward shift in the utility frontier, identifying a potential Pareto improving move. Two particular choices of $\mathbf{U}$ are typically considered in welfare analysis. First, choosing $\mathbf{U}$ to satisfy $\mathrm{W}(\mathbf{U}, \mathbf{t}, \mathbf{q}, \mathrm{Y})=0$ implies that $\Delta \mathrm{W} \equiv \mathrm{W}\left(\mathbf{U}, \mathbf{t}^{\prime} \mathbf{q}^{\prime}, \mathrm{Y}\right)$, corresponding to a "compensating variation" measure. Second, choosing $\mathbf{U}$ to satisfy $\mathrm{W}(\mathbf{U}$, $\left.\mathbf{t}^{\prime}, \mathbf{q}^{\prime}, \mathrm{Y}\right)=0$ implies that $\Delta \mathrm{W} \equiv-\mathrm{W}(\mathbf{U}, \mathbf{t}, \mathbf{q}, \mathrm{Y})$, corresponding to an "equivalent variation" measure. We proceed with our analysis below assuming that $\mathbf{U}$ follows one of these two choices. ${ }^{5}$ On that basis, our analysis of the aggregate efficiency of trade policy reform will rely on $\left[\mathrm{W}\left(\mathbf{U}, \mathbf{t}^{\prime} \mathbf{q}^{\prime}, \mathrm{Y}\right)-\mathrm{W}(\mathbf{U}, \mathbf{t}, \mathbf{q}, \mathrm{Y})\right]$.

What about distribution effects? $\mathrm{W}(\mathbf{U}, \mathbf{t}, \mathbf{q}, \mathrm{Y})$ provides a measure of aggregate benefit, i.e. it is the sum of individual benefit across all households. Evaluating how individual welfare gets distributed is more challenging for three reasons. First, it involves the distribution of profit $\pi_{\mathrm{j}}$ among households. Any change in profit distribution affects the distribution of welfare among households. Second, the way tariff revenue is distributed matters. The redistribution of tariff revenue $\mathbf{t}^{\mathrm{T}} \mathbf{m}_{\mathrm{A}}$ is captured in Equation (7). How this redistribution takes place affects the distribution of welfare among households. Third, who captures the quota rents $\lambda^{*}$ matters. This depends on how trade policy is implemented. For example, under "voluntary export restraints", the quota rents get captured by exporters. Alternatively, when import quotas are auctioned among exporters, the importing country typically captures the quota rents. This illustrates how the distribution of quota rents can affect the distribution of welfare among households. Since it allows for an arbitrary number of firms and households, our analysis of aggregate

${ }^{5}$ Holding $\mathbf{U}$ constant, it means that our analysis of consumer behavior below should be interpreted in terms of Hicksian compensated behavior. 
efficiency remains valid under alternative distribution schemes. Each distribution scheme simply involves choosing a different point $\mathbf{U}$ on the utility frontier $\left\{\mathbf{U}^{\prime}\right.$ : $\left.\mathrm{W}\left(\mathbf{U}^{\prime}, \mathbf{t}, \mathbf{q}, \mathrm{Y}\right)=0\right\}$. In this context, it should be understood that the choice of $\mathbf{U}$ depends on the distribution rules used in economic and trade policy. The analysis of efficiency presented in this paper is conditional on $\mathbf{U}$. When using a compensating variation measure, this means that $\mathbf{U}$ satisfying $\mathrm{W}(\mathbf{U}, \mathbf{t}, \mathbf{q}, \mathrm{Y})=0$ reflects the distribution rules under trade policy (t, q). Alternatively, when using an equivalent variation measure, it means that $\mathbf{U}$ satisfying $\mathrm{W}\left(\mathbf{U}, \mathbf{t}^{\prime}, \mathbf{q}^{\prime}, \mathrm{Y}\right)=0$ reflects the distribution rules under trade policy (t', $\left.\mathbf{q}^{\prime}\right)$.

Next, we analyze the general welfare effects of a change in trade policy from $(\mathbf{t}, \mathbf{q})$ to $\left(\mathbf{t}^{\prime}, \mathbf{q}^{\prime}\right)$. Our analysis will rely on the following result. (See the proof in the Appendix).

Proposition 1: For any $(\mathbf{t}, \mathbf{q})$ and $\left(\mathbf{t}^{\prime}, \mathbf{q}^{\prime}\right)$,

$$
\begin{aligned}
& \lambda^{*}\left(\mathbf{U}, \mathbf{t}^{\prime}, \mathbf{q}^{\prime}, \mathrm{Y}\right)^{\mathrm{T}}\left[\mathbf{q}^{\prime}-\mathbf{q}\right]+\mathbf{t}^{\mathrm{T}^{\mathrm{T}}}\left[\mathbf{m}_{\mathrm{A}}{ }^{*}\left(\mathbf{U}, \mathbf{t}^{\prime}, \mathbf{q}^{\prime}, \mathrm{Y}\right)\right. \\
& \left.\quad-\mathbf{m}_{\mathrm{A}}^{*}(\mathbf{U}, \mathbf{t}, \mathbf{q}, \mathrm{Y})\right] \\
& \leq \mathrm{W}\left(\mathbf{U}, \mathbf{t}^{\prime} \mathbf{q}, \mathrm{Y}\right)-\mathrm{W}(\mathbf{U}, \mathbf{t}, \mathbf{q}, \mathrm{Y}) \\
& \quad \leq \lambda^{*}(\mathbf{U}, \mathbf{t}, \mathbf{q}, \mathrm{Y})^{\mathrm{T}}\left[\mathbf{q}^{\prime}-\mathbf{q}\right] \\
& \quad+\mathbf{t}^{\mathrm{T}}\left[\mathbf{m}_{\mathrm{A}}{ }^{*}\left(\mathbf{U}, \mathbf{t}^{\prime}, \mathbf{q}^{\prime}, \mathrm{Y}\right)-\mathbf{m}_{\mathrm{A}}{ }^{*}(\mathbf{U}, \mathbf{t}, \mathbf{q}, \mathrm{Y})\right] .
\end{aligned}
$$

Proposition 1 provides a general characterization of the aggregate effects of trade policy. First, note that choosing $\mathbf{q}^{\prime}=\infty$ implies that the quota constraint (5) is non-binding and that the associated quota rent is zero: $\lambda^{*}\left(\mathbf{U}, \mathbf{t}^{\prime}, \infty, Y\right)=0$ for any $\mathbf{t}^{\prime}$. Then, choosing $\mathbf{t}^{\prime}=0$ and $\mathbf{q}^{\prime}=\infty$, and for any trade policy $(\mathbf{t}, \mathbf{q})$, the first inequality in equation (8) gives: $\mathrm{W}(\mathbf{U}, 0, \infty, \mathrm{Y}) \geq \mathrm{W}(\mathbf{U}, \mathbf{t}, \mathbf{q}, \mathrm{Y})$. Associating $\left(\mathbf{t}^{\prime}, \mathbf{q}^{\prime}\right)=(0, \infty)$ with competitive markets in the absence of trade policy, this gives the well-known result that aggregate welfare is maximized in the absence of policy distortions, and that perfectly competitive markets are Pareto efficient. In this context, any trade policy $(\mathbf{t}, \mathbf{q})$ where $\mathbf{t} \neq 0$ and the quotas $\mathbf{q}$ are binding is in general inefficient and tends to lower aggregate benefit, with $[\mathrm{W}(\mathbf{U}, 0, \infty, \mathrm{Y})-\mathrm{W}(\mathbf{U}, \mathbf{t}, \mathbf{q}, \mathrm{Y})] \geq 0$ providing a measure of the aggregate welfare loss associated with an inwardshift in the utility frontier.

Second, for any (t, $\mathbf{q})$ and (t', $\left.\mathbf{q}^{\prime}\right)$, Equation (8) implies

$$
\begin{aligned}
& {\left[\lambda^{*}\left(\mathbf{U}, \mathbf{t}^{\prime}, \mathbf{q}^{\prime}, \mathbf{Y}\right)-\lambda^{*}(\mathbf{U}, \mathbf{t}, \mathbf{q}, \mathrm{Y})\right]^{\mathrm{T}}\left[\mathbf{q}^{\prime}-\mathbf{q}\right] } \\
+ & {\left[\mathbf{t}^{\prime}-\mathbf{t}\right]^{\mathrm{T}}\left[\mathbf{m}_{\mathrm{A}}{ }^{*}\left(\mathbf{U}, \mathbf{t}^{\prime}, \mathbf{q}^{\prime}, \mathrm{Y}\right)-\mathbf{m}_{\mathrm{A}}{ }^{*}(\mathbf{U}, \mathbf{t}, \mathbf{q}, \mathrm{Y})\right] } \\
& \leq 0 .
\end{aligned}
$$

When quotas do not change ( $\left.\mathbf{q}^{\prime}=\mathbf{q}\right)$, Equation (9) becomes $\left[\mathbf{t}^{\prime}-\mathbf{t}\right]^{\mathrm{T}}\left[\mathbf{m}_{\mathrm{A}}{ }^{*}\left(\mathbf{U}, \mathbf{t}^{\prime}, \mathbf{q}, \mathbf{Y}\right)-\mathbf{m}_{\mathrm{A}}{ }^{*}(\mathbf{U}, \mathbf{t}, \mathbf{q}, \mathrm{Y})\right] \leq 0$. This is the well-known result that any ceteris paribus increase in import tariffs $\left(\mathbf{t}^{\prime}>\mathbf{t}\right)$ tends to reduce imports $\mathbf{m}_{\mathrm{A}}{ }^{*}$. Similarly, if tariffs do not change $\left(\mathbf{t}^{\prime}=\mathbf{t}\right)$, Equation (9) becomes $\left[\lambda^{*}\left(\mathbf{U}, \mathbf{t}, \mathbf{q}^{\prime}, \mathbf{Y}\right)-\lambda^{*}(\mathbf{U}, \mathbf{t}, \mathbf{q}, Y)\right]^{\mathrm{T}}\left[\mathbf{q}^{\prime}-\mathbf{q}\right] \leq$ 0 . Again, this is the well-known result that any ceteris paribus increase in import quotas $\left(\mathbf{q}^{\prime}>\mathbf{q}\right)$ tends to de- crease the quota rents $\lambda^{*}$. Note that these results are global as they apply for any discrete change in trade policy.

Third, Equation (8) presents bounds on the change in aggregate benefit when trade policy changes from $(\mathbf{t}, \mathbf{q})$ and ('t', $\left.\mathbf{q}^{\prime}\right)$. From the lower bound in equation (8), it follows that a sufficient condition for $\left[\mathrm{W}\left(\mathbf{U}, \mathbf{t}^{\prime}, \mathbf{q}^{\prime}, \mathrm{Y}\right)-\right.$ $\mathrm{W}(\mathbf{U}, \mathbf{t}, \mathbf{q}, \mathrm{Y})] \geq 0$ is

$$
\begin{aligned}
& \lambda^{*}\left(\mathbf{U}, \mathbf{t}^{\prime}, \mathbf{q}^{\prime}, \mathrm{Y}\right)^{\mathrm{T}}\left[\mathbf{q}^{\prime}-\mathbf{q}\right] \\
& +\mathbf{t}^{\mathbf{T}^{\mathrm{T}}}\left[\mathbf{m}_{\mathrm{A}}{ }^{*}\left(\mathbf{U}, \mathbf{t}^{\prime}, \mathbf{q}^{\prime}, \mathrm{Y}\right)-\mathbf{m}_{\mathrm{A}}{ }^{*}(\mathbf{U}, \mathbf{t}, \mathbf{q}, \mathrm{Y})\right] \\
& \quad \geq 0 .
\end{aligned}
$$

Thus, Equation (10a) is a sufficient condition for trade policy reform from $(\mathbf{t}, \mathbf{q})$ and $\left(\mathbf{t}^{\prime}, \mathbf{q}^{\prime}\right)$ to improve efficiency (by increasing aggregate benefit and thus shifting up the utility frontier). It applies under general conditions involving discrete changes in both tariffs and quotas. This includes as special cases some well-known results. For example, in situations where there is a move to eliminating all tariffs (with $\mathbf{t}^{\prime}=0$ ), then given $\lambda^{*} \geq \mathbf{0}$, Equation (10a) implies that any scenario where quotas are relaxed $\left(\mathbf{q}^{\prime}>\mathbf{q}\right)$ is efficiency improving. Alternatively, when quotas do not change $\left(\mathbf{q}^{\prime}=\mathbf{q}\right)$, then using Equation (9), Equation (10a) always holds under any proportional reduction in tariffs (e.g., [14]). This wellknown result (that a proportional decline in all tariffs tends to be efficiency improving) has guided trade policy reform supported by WTO over the last decade.

Similarly, from the upper bound in Equation (8), it follows that a necessary condition for $\left[\mathrm{W}\left(\mathbf{U}, \mathbf{t}^{\prime}, \mathbf{q}^{\prime}, \mathrm{Y}\right)\right.$ $\mathrm{W}(\mathbf{U}, \mathbf{t}, \mathbf{q}, \mathrm{Y})] \geq 0$ is

$$
\begin{aligned}
& \lambda^{*}(\mathbf{U}, \mathbf{t}, \mathbf{q}, \mathrm{Y})^{\mathrm{T}}\left[\mathbf{q}^{\prime}-\mathbf{q}\right] \\
& +\mathbf{t}^{\mathrm{T}}\left[\mathbf{m}_{\mathrm{A}}{ }^{*}\left(\mathbf{U}, \mathbf{t}^{\prime}, \mathbf{q}^{\prime}, \mathrm{Y}\right)-\mathbf{m}_{\mathrm{A}}{ }^{*}(\mathbf{U}, \mathbf{t}, \mathbf{q}, \mathrm{Y})\right] \\
& \geq 0 .
\end{aligned}
$$

It means that Equation (10b) is a necessary condition for trade policy reform from $(\mathbf{t}, \mathbf{q})$ and $\left(\mathbf{t}^{\prime}, \mathbf{q}^{\prime}\right)$ to improve efficiency (by increasing aggregate benefit and shifting up the utility frontier). Alternatively, finding any situation where Equation (10b) does not hold implies an aggregate welfare loss. Then, the policy reform from $(\mathbf{t}, \mathbf{q})$ and ('t', q') cannot be a Pareto improvement. This would identify rent-seeking behavior. Indeed, such policy reform can be a rational move only if it implies a redistribution of welfare toward the "rent seekers" who benefit at the expense of others (as efficiency and aggregate benefit decline and the utility frontier shifts down).

\section{Trade Policy Analysis under Induced Innovation}

So far, we have explored scenarios of trade policy reform represented by a change in policy instruments from $(\mathbf{t}, \mathbf{q})$ to $\left(\mathbf{t}^{\prime}, \mathbf{q}^{\prime}\right)$. We now consider the case where such policy 
changes are associated with technological innovation. Induced innovation was discussed in Section 2 at the firm level. We showed in Equation (2) how prices affect firm technology choices in long run equilibrium. The analysis is now extended to the aggregate level in the context of trade policy.

We know that the direct effect of import tariffs and quotas on specific commodities is to increase their corresponding prices in domestic markets. But they also influence the prices of all goods through market equilibrium effects. This applies in particular to substitute goods. Market equilibrium prices of substitute goods tend to move together. This means that, when the direct effect of an economic policy is to increase the price of some goods, induced innovation would help stimulate the adoption of technologies supporting the production of substitute goods. Such general equilibrium effects are analyzed below.

From Equations (1) and (6), firms behave so as to maximize profit, conditional on prices $(\mathbf{p}+\boldsymbol{\lambda}+\mathbf{t})$ for firms in $\boldsymbol{M}_{\mathrm{A}}$, and prices $\mathbf{p}$ for firms in $\boldsymbol{M}_{\mathrm{B}}$. From Lemma 1 and Equations (A2)-(A3) in the Appendix, this is fully consistent with the maximization of (distorted) aggregate benefit. And from Equation (2), the firm profit maximization motive extends to firm technology choice in the long run. Denote the technology options available to all firms by $\mathbf{Y}=\left\{\left(\mathrm{Y}_{\mathrm{j}}{ }^{1}, \mathrm{Y}_{\mathrm{j}}{ }^{2}, \ldots\right), \mathrm{j} \in M\right\}$, where $\mathrm{Y}_{\mathrm{j}}^{\mathrm{i}}$ is the $\mathrm{i}$-th technology option available to the $\mathrm{j}$-th firm. It means that, in the long run, for a given $\mathbf{U}$ and under trade policy (t, q), technology choice are made as follows: ${ }^{6}$

$$
\mathrm{Y}^{*}(\mathbf{U}, \mathbf{t}, \mathbf{q}) \in \operatorname{argmax}_{\mathrm{Y}}\{\mathrm{W}(\mathbf{U}, \mathbf{t}, \mathbf{q}, \mathrm{Y}): \mathrm{Y} \in \mathbf{Y}\} .
$$

Under trade policy reform, this identifies two possible technology choices: $\mathrm{Y}^{*}(\mathbf{U}, \mathbf{t}, \mathbf{q})$ under policy instruments $(\mathbf{t}, \mathbf{q})$, and $\mathrm{Y}^{*}\left(\mathbf{U}, \mathbf{t}^{\prime}, \mathbf{q}^{\prime}\right)$ under policy instruments $\left(\mathbf{t}^{\prime}, \mathbf{q}^{\prime}\right)$. As discussed in Section 2, this allows heterogeneous technologies across firms. Perhaps more importantly, under induced innovation, this allows for entry/exit and for technology adoption decisions to vary among firms (e.g., between "domestic firms" in $\boldsymbol{M}_{\mathrm{A}}$ and "exporting firms" in $\boldsymbol{M}_{\mathrm{B}}$ ).

Consider the case of a policy reform associated with a change from $(\mathbf{t}, \mathbf{q})$ to $\left(\mathbf{t}^{\prime}, \mathbf{q}^{\prime}\right)$, with $(\mathbf{t}, \mathbf{q}) \neq\left(\mathbf{t}^{\prime}, \mathbf{q}^{\prime}\right)$. We focus our attention on situations where induced innovation plays a role, i.e. where $\mathrm{Y}^{*}(\mathbf{U}, \mathbf{t}, \mathbf{q}) \neq \mathrm{Y}^{*}\left(\mathbf{U}, \mathbf{t}^{\prime}, \mathbf{q}^{\prime}\right)$. First, consider the situation before the policy change. It corresponds to policy instruments $(\mathbf{t}, \mathbf{q})$. Assuming that this trade policy has been in place for an extended period of time, the associated technology choice is $\mathrm{Y}^{*}(\mathbf{U}, \mathbf{t}, \mathbf{q})$. Second, consider a policy change from $(\mathbf{t}, \mathbf{q})$ to $\left(\mathbf{t}^{\prime}, \mathbf{q}^{\prime}\right)$. There are now two possible scenarios. There is a short run scenario $(\mathrm{S})$ where firms have not had enough time to

${ }^{6}$ But some abuse of notation, this maximization problem assumes that one technology $Y_{j}{ }^{i}$ is chosen for each firm, $j \in N$. modify their technology, implying that firms are constrained to face the original feasible set $\mathrm{Y}^{*}(\mathbf{U}, \mathbf{t}, \mathbf{q})$. And there is a long run scenario (L) where firms do adjust their technology and choose $\mathrm{Y}^{*}\left(\mathbf{U}, \mathbf{t}^{\prime}, \mathbf{q}^{\prime}\right)$. What is the difference between these two scenarios? Answering this question requires exploring how the effects of policy change differ between the short run and the long run.

First, consider the short run scenario (S). Denote the optimal technology chosen under policy $(\mathbf{t}, \mathbf{q})$ by $\mathrm{Y}^{\mathrm{S}} \equiv$ $\mathrm{Y}^{*}(\mathbf{U}, \mathbf{t}, \mathbf{q})$. Keeping the feasible set $\mathrm{Y}$ in its original state $\mathrm{Y}^{\mathrm{S}}$, the short run welfare effects of trade policy reform can be measured as

$$
\Delta \mathrm{W}^{\mathrm{S}} \equiv \mathrm{W}\left(\mathbf{U}, \mathbf{t}^{\prime}, \mathbf{q}^{\prime}, \mathrm{Y}^{\mathrm{S}}\right)-\mathrm{W}\left(\mathbf{U}, \mathbf{t}, \mathbf{q}, \mathrm{Y}^{\mathrm{S}}\right)
$$

Second, consider the long run scenario (L) and the associated welfare changes due to a policy change from ( $t$, q) to $\left(\mathbf{t}^{\prime}, \mathbf{q}^{\prime}\right)$. Denote the optimal technology chosen under policy $\left(\mathbf{t}^{\prime}, \mathbf{q}^{\prime}\right)$ by $\mathrm{Y}^{\mathrm{L}} \equiv \mathrm{Y}^{*}\left(\mathbf{U}, \mathbf{t}^{\prime}, \mathbf{q}^{\prime}\right)$. In the long run, the welfare effects of trade policy reform can be measured as

$$
\Delta \mathrm{W}^{\mathrm{L}} \equiv \mathrm{W}\left(\mathbf{U}, \mathbf{t}^{\prime}, \mathbf{q}^{\prime}, \mathrm{Y}^{\mathrm{L}}\right)-\mathrm{W}\left(\mathbf{U}, \mathbf{t}, \mathbf{q}, \mathrm{Y}^{\mathrm{S}}\right)
$$

which allows a switch from technology $\mathrm{Y}^{\mathrm{S}}$ to $\mathrm{Y}^{\mathrm{L}}$ as trade policy changes from $(\mathbf{t}, \mathbf{q})$ to $\left(\mathbf{t}^{\prime}, \mathbf{q}^{\prime}\right)$. This raises the question: how does $\Delta \mathrm{W}^{\mathrm{L}}$ differ from $\Delta \mathrm{W}^{\mathrm{S}}$ ? Our analysis presented below answers this question. In the process, we will gain new and useful information on how induced innovation and trade policy interact with each other. ${ }^{7}$

Our analysis explores the economic and welfare implications of induced innovation. Our main result is stated next. (See the proof in the Appendix)

Proposition 2 (Global LeChatelier results): For any policy change from $(\mathbf{t}, \mathbf{q})$ to $\left(\mathbf{t}^{\prime}, \mathbf{q}^{\prime}\right)$,

$$
\begin{aligned}
0 & \leq \Delta \mathrm{W}^{\mathrm{L}}-\Delta \mathrm{W}^{\mathrm{S}} \\
& \leq\left[\lambda^{*}\left(\mathbf{U}, \mathbf{t}, \mathbf{q}, \mathrm{Y}^{\mathrm{L}}\right)-\lambda^{*}\left(\mathbf{U}, \mathbf{t}^{\prime}, \mathbf{q}^{\prime}, \mathrm{Y}^{\mathrm{S}}\right)\right]^{\mathrm{T}}\left[\mathbf{q}^{\prime}-\mathbf{q}\right] \\
& +\mathbf{t}^{\mathrm{T}}\left[\mathbf{m}_{\mathrm{A}}{ }^{*}\left(\mathbf{U}, \mathbf{t}^{\prime}, \mathbf{q}^{\prime}, \mathrm{Y}^{\mathrm{L}}\right)-\mathbf{m}_{\mathrm{A}}{ }^{*}\left(\mathbf{U}, \mathbf{t}, \mathbf{q}, \mathrm{Y}^{\mathrm{L}}\right)\right] \\
& -\mathbf{t}^{\prime}{ }^{\mathrm{T}}\left[\mathbf{m}_{\mathrm{A}}{ }^{*}\left(\mathbf{U}, \mathbf{t}^{\prime}, \mathbf{q}^{\prime}, \mathrm{Y}^{\mathrm{S}}\right)-\mathbf{m}_{\mathrm{A}}{ }^{*}\left(\mathbf{U}, \mathbf{t}, \mathbf{q}, \mathrm{Y}^{\mathrm{S}}\right)\right] .
\end{aligned}
$$

Equation (13) shows that the general implications of induced innovation for market equilibrium prices, quantities, and welfare. Importantly, these results hold globally under any discrete changes in trade policy. Equation (13) gives LeChatelier results related to the effects of trade policy under induced innovation. These results appear to be new. They apply globally for any discrete change from $(\mathbf{t}, \mathbf{q})$ to $\left(\mathbf{t}^{\prime}, \mathbf{q}^{\prime}\right)$. The economic and welfare implications of Equation (13) are further discussed below.

While LeChatelier effects have been examined before

\footnotetext{
${ }^{7}$ Note that induced innovation involves choosing among technologies, assuming that they are "on the shelf". While our discussion below focuses on this case, the analysis could be easily extended to more general cases of technological changes. It could be used to show that technological progress can improve aggregate welfare beyond the gains obtained from induced innovation.
} 
in the context of trade (e.g., $[8,9])$, they were developed for "small changes" in trade policy under differentiability assumptions. This suggests the existence of a local version of Proposition 2. Such local results are presented next. (See the proof in the Appendix).

Proposition 3 (Local LeChatelier results): Assume that $\mathrm{W}(\mathbf{U}, \mathbf{t}, \mathbf{q}, \mathrm{Y})$ is differentiable in $(\mathbf{t}, \mathbf{q})$, that $\lambda^{*}(\mathbf{U}, \mathbf{t}, \mathbf{q}, \mathrm{Y})$ is a continuous function of $(\mathbf{t}, \mathbf{q})$, and that $\mathbf{m}_{\mathrm{A}}{ }^{*}(\mathbf{U}, \mathbf{t}, \mathbf{q}, \mathrm{Y})$ is continuously differentiable in $(\mathbf{t}, \mathbf{q})$. Then, considering a small change in trade policy ( $d \mathbf{t}, \mathbf{d q})$ in the neighborhood of $(\mathbf{t}, \mathbf{q})$,

$$
\begin{aligned}
0 & \leq \mathrm{dW}^{\mathrm{L}}-\mathrm{dW}^{\mathrm{S}} \\
& =\left[\lambda^{*}\left(\mathbf{U}, \mathbf{t}, \mathbf{q}, \mathrm{Y}^{\mathrm{L}}\right)-\lambda^{*}\left(\mathbf{U}, \mathbf{t}, \mathbf{q}, \mathrm{Y}^{\mathrm{S}}\right)\right]^{\mathrm{T}} \mathrm{d} \mathbf{q} \\
& +\mathbf{t}^{\mathrm{T}}\left[\mathrm{dm}_{\mathrm{A}}{ }^{*}\left(\mathbf{U}, \mathbf{t}, \mathbf{q}, \mathrm{Y}^{\mathrm{L}}\right)-\mathrm{dm}_{\mathrm{A}}{ }^{*}\left(\mathbf{U}, \mathbf{t}, \mathbf{q}, \mathrm{Y}^{\mathrm{S}}\right)\right],
\end{aligned}
$$

where $\mathrm{d} \mathbf{m}_{\mathrm{A}}{ }^{*}(\mathbf{U}, \mathbf{t}, \mathbf{q}, \mathrm{Y})=\left[\partial \mathbf{m}_{\mathrm{A}}{ }^{*}(\mathbf{U}, \mathbf{t}, \mathbf{q}, \mathrm{Y}) / \partial \mathbf{t}\right] \mathrm{d} \mathbf{t}+$ $\left[\partial \mathbf{m}_{\mathrm{A}}{ }^{*}(\mathbf{U}, \mathbf{t}, \mathbf{q}, \mathrm{Y}) / \partial \mathbf{q}\right] \mathrm{d} \mathbf{q}$.

Proposition 3 is a local version of the LeChatelier results presented in Proposition 2. Indeed, expression (14) is a special case of (13) obtained under differentiability assumptions and considering only a small change in trade policy (dt, dq) in the neighborhood of (t, q). Comparing equations (13) and (14), it is clear that the global results stated in Equation (13) are more general: they apply for any discrete policy change from $(\mathbf{t}, \mathbf{q})$ to $\left(\mathbf{t}^{\prime}, \mathbf{q}^{\prime}\right)$, and without imposing restrictive assumptions (e.g., they apply without assuming supermodularity or differentiability). Implications of these results are discussed next.

\section{Implications}

Propositions 2 and 3 give information on the welfare difference from a trade policy change between the short run (S) and the long run (L): $\Delta \mathrm{W}^{\mathrm{L}}-\Delta \mathrm{W}^{\mathrm{S}}$. From Equations (13) and (14), this difference has a general lower bound of 0 . It implies that the aggregate welfare effect of a policy change is always at least as large in the long run as in the short run. This is a general and intuitive result: induced innovation tends to generate long run benefits that are at least as large as the associated short run benefits. In the context of trade policy changes, this means that the efficiency effects of trade policy changes become more positive (or less negative) due to induced innovation. Importantly, this result holds under very general conditions.

The global LeChatelier results given in Equation (13) provide useful information on the welfare and economic impact of trade policy. From Equation (13), the welfare change $\left[\Delta \mathrm{W}^{\mathrm{L}}-\Delta \mathrm{W}^{\mathrm{S}}\right]$ has a general upper bound equal to: $\left[\lambda^{*}\left(\mathbf{U}, \mathbf{t}, \mathbf{q}, \mathrm{Y}^{\mathrm{L}}\right)-\lambda^{*}\left(\mathbf{U}, \mathbf{t}^{\prime}, \mathbf{q}^{\prime}, \mathrm{Y}^{\mathrm{S}}\right)\right]^{\mathrm{T}}\left[\mathbf{q}^{\prime}-\mathbf{q}\right]+\mathbf{t}^{\mathrm{T}}\left[\mathbf{m}_{\mathrm{A}}{ }^{*}(\mathbf{U}\right.$, $\left.\left.\mathbf{t}^{\prime}, \mathbf{q}^{\prime}, \mathrm{Y}^{\mathrm{L}}\right)-\mathbf{m}_{\mathrm{A}}{ }^{*}\left(\mathbf{U}, \mathbf{t}, \mathbf{q}, \mathrm{Y}^{\mathrm{L}}\right)\right]-\mathbf{t}^{\mathrm{T}}\left[\mathbf{m}_{\mathrm{A}}{ }^{*}\left(\mathbf{U}, \mathbf{t}^{\prime}, \mathbf{q}^{\prime}, \mathrm{Y}^{\mathrm{S}}\right)-\right.$ $\left.\mathbf{m}_{\mathrm{A}}{ }^{*}\left(\mathbf{U}, \mathbf{t}, \mathbf{q}, \mathrm{Y}^{\mathrm{S}}\right)\right] \geq 0$. This upper bound provides a measure of the largest possible welfare gain generated by induced innovation. As discussed below, this upper bound also provides useful information on the interaction effects between induced innovation and trade policy reform.

First, consider the case where only tariffs change. Then, when quota policy does not change $\left(\mathbf{q}^{\prime}=\mathbf{q}\right)$ and tariff policy changes from $\mathbf{t}$ to $\mathbf{t}$ ', Equation (13) gives the following important result:

$$
\begin{aligned}
0 & \leq \Delta \mathrm{W}^{\mathrm{L}}-\Delta \mathrm{W}^{\mathrm{S}} \\
& \leq \mathbf{t}^{\mathrm{T}}\left[\mathbf{m}_{\mathrm{A}}{ }^{*}\left(\mathbf{U}, \mathbf{t}^{\prime}, \mathbf{q}, \mathrm{Y}^{\mathrm{L}}\right)-\mathbf{m}_{\mathrm{A}}{ }^{*}\left(\mathbf{U}, \mathbf{t}, \mathbf{q}, \mathrm{Y}^{\mathrm{L}}\right)\right] \\
& -\mathbf{t}^{{ }^{\mathrm{T}}}\left[\mathbf{m}_{\mathrm{A}}{ }^{*}\left(\mathbf{U}, \mathbf{t}, \mathbf{q}, \mathrm{Y}^{\mathrm{S}}\right)-\mathbf{m}_{\mathrm{A}}{ }^{*}\left(\mathbf{U}, \mathbf{t}, \mathbf{q}, \mathrm{Y}^{\mathrm{S}}\right)\right] .
\end{aligned}
$$

To interpret Equation (15), consider the case of an increase in tariff, with $\mathbf{t}^{\prime}>\mathbf{t} \geq 0$. From Equation (9), we know that, ceteris paribus, any tariff increase tends to have negative effects on trade $\mathbf{m}_{\mathrm{A}}{ }^{*}$. In this context, Equation (15) implies that a weighted sum (with tariffs as weights) of the trade reduction due to higher tariffs tends to smaller in the long run compared to the short run. This global LeChatelier effect indicates how tariff reform can affect trade under induced innovation. To illustrate, letting $\mathbf{t}^{\prime} \equiv \mathbf{t}+\Delta \mathbf{t}$ and noting that $\mathbf{m}_{\mathrm{A}}{ }^{*}\left(\mathbf{U}, \mathbf{t}, \mathbf{q}, \mathrm{Y}^{\mathrm{L}}\right)=\mathbf{m}_{\mathrm{A}}{ }^{*}(\mathbf{U}$, $\mathbf{t}, \mathbf{q}, \mathrm{Y}^{\mathrm{S}}$ ), Equation (15) implies that:

$$
\begin{aligned}
\mathbf{t}^{\mathrm{T}} & {\left[\mathbf{m}_{\mathrm{A}}{ }^{*}\left(\mathbf{U}, \mathbf{t}^{\prime}, \mathbf{q}, \mathrm{Y}^{\mathrm{L}}\right)-\mathbf{m}_{\mathrm{A}}{ }^{*}\left(\mathbf{U}, \mathbf{t}^{\prime}, \mathbf{q}, \mathrm{Y}^{\mathrm{S}}\right)\right] } \\
& \geq \Delta \mathbf{t}^{\mathrm{T}}\left[\mathbf{m}_{\mathrm{A}}{ }^{*}\left(\mathbf{U}, \mathbf{t}^{\prime}, \mathbf{q}, \mathrm{Y}^{\mathrm{S}}\right)-\mathbf{m}_{\mathrm{A}}{ }^{*}\left(\mathbf{U}, \mathbf{t}, \mathbf{q}, \mathrm{Y}^{\mathrm{S}}\right)\right] \\
& \leq 0,
\end{aligned}
$$

where the last inequality follows from Equation (9). Equation (16) implies that a change in import value associated with an induced adjustment in technology from $Y^{S}$ to $\mathrm{Y}^{\mathrm{L}}, \mathbf{t}^{\mathrm{T}}\left[\mathbf{m}_{\mathrm{A}}{ }^{*}\left(\mathbf{U}, \mathbf{t}^{\prime}, \mathbf{q}, \mathrm{Y}^{\mathrm{L}}\right)-\mathbf{m}_{\mathrm{A}}{ }^{*}\left(\mathbf{U}, \mathbf{t}^{\prime}, \mathbf{q}, \mathrm{Y}^{\mathrm{S}}\right)\right]$, is at least as large as the corresponding short run effect of tariff change, $\Delta \mathbf{t}^{\mathrm{T}}\left[\mathbf{m}_{\mathrm{A}}{ }^{*}\left(\mathbf{U}, \mathbf{t}^{\prime}, \mathbf{q}, \mathrm{Y}^{\mathrm{S}}\right)-\mathbf{m}_{\mathrm{A}}{ }^{*}\left(\mathbf{U}, \mathbf{t}, \mathbf{q}, \mathrm{Y}^{\mathrm{S}}\right)\right] \leq$ 0 . This LeChatelier result appears to be new. Note that it does not imply that induced innovation necessarily reduces the adverse effects of tariffs on trade. But Equation (16) establishes a lower bound on the trade effects, $\mathbf{t}^{\mathrm{T}}$ $\left[\mathbf{m}_{\mathrm{A}}{ }^{*}\left(\mathbf{U}, \mathbf{t}^{\prime}, \mathbf{q}, \mathrm{Y}^{\mathrm{L}}\right)-\mathbf{m}_{\mathrm{A}}{ }^{*}\left(\mathbf{U}, \mathbf{t}^{\prime}, \mathbf{q}, \mathrm{Y}^{\mathrm{S}}\right)\right]$, and it states that this lower bound is non-positive and given by $\Delta \mathbf{t}^{\mathrm{T}}$ $\left[\mathbf{m}_{\mathrm{A}}{ }^{*}\left(\mathbf{U}, \mathbf{t}^{\prime}, \mathbf{q}, \mathrm{Y}^{\mathrm{S}}\right)-\mathbf{m}_{\mathrm{A}}{ }^{*}\left(\mathbf{U}, \mathbf{t}, \mathbf{q}, \mathrm{Y}^{\mathrm{S}}\right)\right]$. This indicates that induced innovation could stimulate trade, with $\mathbf{t}^{\mathrm{T}}\left[\mathbf{m}_{\mathrm{A}}{ }^{*}(\mathbf{U}\right.$, $\left.\left.\mathbf{t}^{\prime}, \mathbf{q}, \mathrm{Y}^{\mathrm{L}}\right)-\mathbf{m}_{\mathrm{A}}{ }^{*}\left(\mathbf{U}, \mathbf{t}^{\prime}, \mathbf{q}, \mathrm{Y}^{\mathrm{S}}\right)\right]>0$, when $\mid \Delta \mathbf{t}^{\mathrm{T}}\left[\mathbf{m}_{\mathrm{A}}{ }^{*}\left(\mathbf{U}, \mathbf{t}^{\prime}\right.\right.$, $\left.\left.\mathbf{q}, \mathrm{Y}^{\mathrm{S}}\right)-\mathbf{m}_{\mathrm{A}}{ }^{*}\left(\mathbf{U}, \mathbf{t}, \mathbf{q}, \mathrm{Y}^{\mathrm{S}}\right)\right] \mid$ is small and tariffs have only modest effects on trade. Alternatively, this suggests that induced innovation could possibly reduce trade, with $\mathbf{t}^{\mathrm{T}}$ $\left[\mathbf{m}_{\mathrm{A}}{ }^{*}\left(\mathbf{U}, \mathbf{t}^{\prime}, \mathbf{q}, \mathrm{Y}^{\mathrm{L}}\right)-\mathbf{m}_{\mathrm{A}}{ }^{*}\left(\mathbf{U}, \mathbf{t}^{\prime}, \mathbf{q}, \mathrm{Y}^{\mathrm{S}}\right)\right]<0$, when $\mid \Delta \mathbf{t}^{\mathrm{T}}$ $\left[\mathbf{m}_{\mathrm{A}}{ }^{*}\left(\mathbf{U}, \mathbf{t}^{\prime}, \mathbf{q}, \mathrm{Y}^{\mathrm{S}}\right)-\mathbf{m}_{\mathrm{A}}{ }^{*}\left(\mathbf{U}, \mathbf{t}, \mathbf{q}, \mathrm{Y}^{\mathrm{S}}\right)\right] \mid$ is large and tariffs have large effects on trade. These results apply globally, i.e. for any change in $\mathbf{t}$, and without imposing differentiability assumptions.

When there is only a change in tariffs (with $\mathrm{dq}=0$ ), and under differentiability assumptions, Equation (14) becomes 


$$
\begin{aligned}
& \mathrm{dW}^{\mathrm{L}}-\mathrm{dW}^{\mathrm{S}} \\
& =\mathbf{t}^{\mathrm{T}}\left[\partial \mathbf{m}_{\mathrm{A}}{ }^{*}\left(\mathbf{U}, \mathbf{t}, \mathbf{q}, \mathrm{Y}^{\mathrm{L}}\right) / \partial \mathbf{t}-\partial \mathbf{m}_{\mathrm{A}}{ }^{*}\left(\mathbf{U}, \mathbf{t}, \mathbf{q}, \mathrm{Y}^{\mathrm{S}}\right) / \partial \mathbf{t}\right] \mathrm{d} \mathbf{t} \\
& \geq 0 .
\end{aligned}
$$

Equation (17) is a local version of Equation (15). It has the following implications. Note that, under differentiability, Equation (9) implies that $\left[\partial \mathbf{m}_{\mathrm{A}}{ }^{*}(\mathbf{U}, \mathbf{t}, \mathbf{q}, \mathrm{Y}) / \partial \mathbf{t}\right]$ is a negative semi-definite matrix, a standard result stating that tariffs tend to have negative effects on trade. This holds in the short run (when $\mathrm{Y}=\mathrm{Y}^{\mathrm{S}}$ ) as well as in long run (when $\mathrm{Y}=\mathrm{Y}^{\mathrm{L}}$ ). Consider a (small) proportional increase in tariff, where $\mathrm{dt}=\mathrm{k} \mathrm{t}>0$ and $\mathrm{k}$ is a small positive scalar. Then, Equation (17) implies that $\mathbf{t}^{\mathrm{T}} \partial \mathbf{m}_{\mathrm{A}}{ }^{*}(\mathbf{U}, \mathbf{t}$, $\left.\left.\mathbf{q}, \mathrm{Y}^{\mathrm{L}}\right) / \partial \mathbf{t}-\partial \mathbf{m}_{\mathrm{A}}{ }^{*}\left(\mathbf{U}, \mathbf{t}, \mathbf{q}, \mathrm{Y}^{\mathrm{S}}\right) / \partial \mathbf{t}\right] \mathbf{t}^{\mathrm{T}} \geq 0$, i.e. that $\left[\partial \mathbf{m}_{\mathrm{A}}{ }^{*}(\mathbf{U}\right.$, $\left.\left.\mathbf{t}, \mathbf{q}, \mathrm{Y}^{\mathrm{L}}\right) / \partial \mathbf{t}-\partial \mathbf{m}_{\mathrm{A}}{ }^{*}\left(\mathbf{U}, \mathbf{t}, \mathbf{q}, \mathrm{Y}^{\mathrm{S}}\right) / \partial \mathbf{t}\right]$ is a positive semidefinite matrix. It means that, under induced innovation, the long run negative effects of tariffs on trade, $\left[\partial \mathbf{m}_{\mathrm{A}}{ }^{*}(\mathbf{U}\right.$, $\left.\left.\mathbf{t}, \mathbf{q}, \mathrm{Y}^{\mathrm{L}}\right) / \partial \mathbf{t}\right]$, tends to smaller than its corresponding short run negative effects, $\left[\partial \mathbf{m}_{\mathrm{A}}{ }^{*}\left(\mathbf{U}, \mathbf{t}, \mathbf{q}, \mathrm{Y}^{\mathrm{S}}\right) / \partial \mathbf{t}\right]$. This is a standard local LeChatelier result: allowing for adjustments in technology tends to reduce the adverse effects of tariffs on trade. This is the result obtained by Neary [8] and Kreickemeier [9]. However, it holds only locally, i.e. only for small changes in tariffs. To see that this LeChatelier result does not hold globally, it suffices to note that $\left\{\mathbf{t}^{\mathrm{T}}\left[\partial \mathbf{m}_{\mathrm{A}}{ }^{*}\left(\mathbf{U}, \mathbf{t}, \mathbf{q}, \mathrm{Y}^{\mathrm{L}}\right) / \partial \mathbf{t}-\partial \mathbf{m}_{\mathrm{A}}{ }^{*}\left(\mathbf{U}, \mathbf{t}, \mathbf{q}, \mathrm{Y}^{\mathrm{S}}\right) / \partial \mathbf{t}\right] \mathrm{d} \mathbf{t}\right\}$ in equation (17) is the local version of the expression on the left-hand side of (16). But as discussed above, the left-hand side of Equation (16) can be either positive or negative. This illustrates the well-known fact that local LeChatelier results do not necessarily apply globally ([7, 10,11]).

Second, consider the case where only quotas change. Then, when tariff policy does not change $\left(\mathbf{t}^{\prime}=\mathbf{t}\right)$ and quota policy changes from $\mathbf{q}$ to $\mathbf{q}$ ', equation (13) gives the following important result:

$$
\begin{aligned}
0 & \leq \Delta \mathrm{W}^{\mathrm{L}}-\Delta \mathrm{W}^{\mathrm{S}} \\
& \leq\left[\lambda^{*}\left(\mathbf{U}, \mathbf{t}, \mathbf{q}, \mathrm{Y}^{\mathrm{L}}\right)-\lambda^{*}\left(\mathbf{U}, \mathbf{t}, \mathbf{q}^{\prime}, \mathrm{Y}^{\mathrm{S}}\right)\right]^{\mathrm{T}}\left[\mathbf{q}^{\prime}-\mathbf{q}\right] \\
& +\mathbf{t}^{\mathrm{T}}\left[\mathbf{m}_{\mathrm{A}}{ }^{*}\left(\mathbf{U}, \mathbf{t}, \mathbf{q}^{\prime}, \mathrm{Y}^{\mathrm{L}}\right)-\mathbf{m}_{\mathrm{A}}{ }^{*}\left(\mathbf{U}, \mathbf{t}, \mathbf{q}^{\prime}, \mathrm{Y}^{\mathrm{S}}\right)\right] .
\end{aligned}
$$

Equation (18) shows the complexity of the general LeChatelier effects associated with a discrete change in quotas under induced innovation. The right-hand side of Equation (18) provides an upper bound on the welfare change $\left[\Delta \mathrm{W}^{\mathrm{L}}-\Delta \mathrm{W}^{\mathrm{S}}\right] \geq 0$. This upper bound involves the difference between quota rents $\lambda^{*}\left(\mathbf{U}, \mathbf{t}, \mathbf{q}^{\prime}, \mathrm{Y}^{\mathrm{S}}\right)$ and $\lambda^{*}(\mathbf{U}$, $\left.\mathbf{t}, \mathbf{q}, \mathrm{Y}^{\mathrm{L}}\right)$. Note the interactions between quota effects and technology: the first quota rent is evaluated at $\left(\mathbf{q}^{\prime}, \mathrm{Y}^{\mathrm{S}}\right)$ while the second is evaluated at $\left(\mathbf{q}, \mathrm{Y}^{\mathrm{L}}\right)$. And in the presence of tariffs (when $\mathbf{t} \neq 0$ ), the upper bound in (18) also includes the term $\left\{\mathbf{t}^{\mathrm{T}}\left[\mathbf{m}_{\mathrm{A}}{ }^{*}\left(\mathbf{U}, \mathbf{t}, \mathbf{q}^{\prime}, \mathrm{Y}^{\mathrm{L}}\right)-\mathbf{m}_{\mathrm{A}}{ }^{*}(\mathbf{U}, \mathbf{t}\right.\right.$, $\left.\left.\left.\mathbf{q}^{\prime}, \mathrm{Y}^{\mathrm{S}}\right)\right]\right\}$. This term reflects changes in tariff revenue (obtained under tariff $\mathbf{t}$ and quota $\mathbf{q}^{\prime}$ ) between the short run (S) and the long run (L). For any discrete change in quota from q to q', Equation (18) gives global LeChatelier effects showing how quota reform can affect quota rents and trade under induced innovation.

While Equation (18) generates general implications of quota reform comparing the short run and the long run, it does not give sharp predictions on how induced innovation can affect quota rents. Yet, Equation (18) implies that the quota rents must change in such a way that the value $\left[\lambda^{*}\left(\mathbf{U}, \mathbf{t}, \mathbf{q}, \mathrm{Y}^{\mathrm{L}}\right)-\lambda^{*}\left(\mathbf{U}, \mathbf{t}, \mathbf{q}^{\prime}, \mathrm{Y}^{\mathrm{S}}\right)\right]^{\mathrm{T}}\left[\mathbf{q}^{\prime}-\mathbf{q}\right]$ is at least as large as $-\mathbf{t}^{\mathrm{T}}\left[\mathbf{m}_{\mathrm{A}}{ }^{*}\left(\mathbf{U}, \mathbf{t}, \mathbf{q}^{\prime}, \mathrm{Y}^{\mathrm{L}}\right)-\mathbf{m}_{\mathrm{A}}{ }^{*}\left(\mathbf{U}, \mathbf{t}, \mathbf{q}^{\prime}\right.\right.$, $\left.\mathrm{Y}^{\mathrm{S}}\right)$ ], the negative of the change in tariff revenue between the short run and the long run. This reflects the presence of significant interactions between tariffs and quotas in the evaluation of global LeChatelier effects related to quota reform.

The analysis simplifies significantly in the absence of tariffs (when $\mathbf{t}=0$ ). Then, the global LeChatelier results in equation (18) reduce to:

$$
\begin{aligned}
& 0 \leq \Delta \mathrm{W}^{\mathrm{L}}-\Delta \mathrm{W}^{\mathrm{S}} \\
& \leq\left[\lambda^{*}\left(\mathbf{U}, \mathbf{t}, \mathbf{q}, \mathrm{Y}^{\mathrm{L}}\right)-\lambda^{*}\left(\mathbf{U}, \mathbf{t}, \mathbf{q}^{\prime}, \mathrm{Y}^{\mathrm{S}}\right)\right]^{\mathrm{T}}\left[\mathbf{q}^{\prime}-\mathbf{q}\right] .
\end{aligned}
$$

This implies that $\left[\lambda^{*}\left(\mathbf{U}, \mathbf{t}, \mathbf{q}, \mathrm{Y}^{\mathrm{L}}\right)-\lambda^{*}\left(\mathbf{U}, \mathbf{t}, \mathbf{q}^{\prime}, \mathrm{Y}^{\mathrm{S}}\right)\right]^{\mathrm{T}}$ $\left[\mathbf{q}^{\prime}-\mathbf{q}\right] \geq 0$, i.e. that any rise in quotas $\mathbf{q}$ tends to increase the difference between the long run quota rents $\lambda^{*}\left(\mathbf{U}, \mathbf{t}, \mathbf{q}^{\prime}, \mathrm{Y}^{\mathrm{L}}\right)$ evaluated at $\mathbf{q}^{\prime}$, and the short run quota rents $\lambda^{*}\left(\mathbf{U}, \mathbf{t}, \mathbf{q}, \mathrm{Y}^{\mathrm{S}}\right)$ evaluated at $\mathbf{q}$. These evaluations involve changes in both technology and quota level, When considering discrete changes in quota policy, note that this does not imply that induced innovation alone (i.e., the switch from $\mathrm{Y}^{\mathrm{S}}$ to $\mathrm{Y}^{\mathrm{L}}$ ) necessarily reduces quota rents.

What about considering small changes in quota policy, dq? Then, in the absence of tariff changes (with dt $=0$ ) and under differentiability assumptions, Equation (14) becomes

$$
\begin{aligned}
& \mathrm{dW}^{\mathrm{L}}-\mathrm{dW}^{\mathrm{S}}=\left[\lambda^{*}\left(\mathbf{U}, \mathbf{t}, \mathbf{q}, \mathrm{Y}^{\mathrm{L}}\right)-\lambda^{*}\left(\mathbf{U}, \mathbf{t}, \mathbf{q}, \mathrm{Y}^{\mathrm{S}}\right)\right]^{\mathrm{T}} \mathrm{d} \mathbf{q} \\
& +\mathbf{t}^{\mathrm{T}}\left[\partial \mathbf{m}_{\mathrm{A}}^{*}\left(\mathbf{U}, \mathbf{t}, \mathbf{q}, \mathrm{Y}^{\mathrm{L}}\right) / \partial \mathbf{q}-\partial \mathbf{m}_{\mathrm{A}}{ }^{*}\left(\mathbf{U}, \mathbf{t}, \mathbf{q}, \mathrm{Y}^{\mathrm{S}}\right) / \partial \mathbf{q}\right] \mathrm{d} \mathbf{q} \\
& \geq 0 .
\end{aligned}
$$

Equation (19) is a local version of Equation (18). Like (18), Equation (19) shows that local LeChatelier results associated with quota changes involve interaction effects between quota policy and tariff policy. Again, when $\mathbf{t} \neq 0$, Equation (19) does not give precise information on the effects of changing quotas on quota rents under induced innovation. Yet, in the simpler case where there is no tariff (with $\mathbf{t}=0$ ), Equation (19) reduces to

$$
\begin{aligned}
& \mathrm{dW}^{\mathrm{L}}-\mathrm{dW}^{\mathrm{S}} \\
& =\left[\lambda^{*}\left(\mathbf{U}, \mathbf{t}, \mathbf{q}, \mathrm{Y}^{\mathrm{L}}\right)-\lambda^{*}\left(\mathbf{U}, \mathbf{t}, \mathbf{q}, \mathrm{Y}^{\mathrm{S}}\right)\right]^{\mathrm{T}} \mathrm{d} \mathbf{q} \geq 0 .
\end{aligned}
$$

Equation (19') is a local version of (18'). It implies that $\left[\lambda^{*}\left(\mathbf{U}, \mathbf{t}, \mathbf{q}, \mathrm{Y}^{\mathrm{L}}\right)-\lambda^{*}\left(\mathbf{U}, \mathbf{t}, \mathbf{q}, \mathrm{Y}^{\mathrm{S}}\right)\right]^{\mathrm{T}} \mathrm{d} \mathbf{q} \geq 0$, i.e. that any rise in quotas $\mathbf{q}$ tends to increase the difference between the long run quota rents $\lambda^{*}\left(\mathbf{U}, \mathbf{t}, \mathbf{q}, \mathrm{Y}^{\mathrm{L}}\right)$ and the short run quota rents $\lambda^{*}\left(\mathbf{U}, \mathbf{t}, \mathbf{q}, \mathrm{Y}^{\mathrm{S}}\right)$. We know from 
Equation (9) that any rise in quotas tends to reduce quota rents. This gives the following local LeChatelier result: when $\mathbf{t}=0$ and for small changes in quotas, induced innovation tends to reduce the corresponding quota rents. But while intuitive, this local result does not hold globally. Indeed, comparing Equations (18') and (19'), this result does not necessarily hold for arbitrary changes in quotas. Again, this illustrates that local LeChatelier results do not necessarily apply globally.

While local LeChatelier results given in Equations (17) and (19') are not new (e.g., [8,9]), our investigation has been innovative in three directions. First, we considered the case of discrete changes in trade policy. This is relevant as actual policy reforms typically involve large changes in policy instruments. Second, we have analyzed the joint effects of tariffs and quotas. Third, we have shown that global LeChatelier results involve an upper bound measure of welfare change. This is given in Equation (15) for tariff changes and Equation (18) for quota changes. But the general result is the one stated in Proposition 2. Indeed, Equation (13) presents the general implications of trade policy reform under induced innovation, providing useful information on both welfare effects and economic adjustments in trade and quota rents.

\section{Concluding Remarks}

This paper has explored the effects of discrete change in trade policy (including both tariffs and quotas) under induced innovation in general equilibrium. It examined the general case where technology and adoption decisions can vary across firms (e.g., domestic versus exporting firms). The interactions between induced innovation and the effects of trade policy give a set of "LeChatelier effects" comparing short run versus long run market equilibrium. In contrast with previous research, the analysis applies globally to arbitrary changes in trade policy and without imposing a priori restrictions (such as supermodularity).

We show that induced innovation tends to reduce the welfare loss generated by distortionary trade policy. It means that ignoring induced innovation would overstate the adverse effects of trade policies. When trade policy is motivated by rent seeking behavior, it also means that induced innovation can tamper the associated inefficiency losses. We examine how induced innovation can influence the adverse effects of tariffs and quotas on trade. We document how tariffs and quotas can interact with each other. Our analysis presents the general implications of trade policy reform under induced innovation, providing useful information on both welfare effects and economic adjustments in trade and quota rents.

\section{Acknowledgements}

I would like to thank Ian Coxhead for useful feedback on an earlier draft of this paper.

\section{REFERENCES}

[1] G. M. Grossman and E. Helpman, "Technology and Trade," In: G. Grossman and K. Rogoff, Eds., Handbook of International Economics, Chapter 25, Vol. 3, Elsevier Science, 1995, pp. 1279-1337.

[2] J. R. Hicks, "The Theory of Wages," Macmillan, London, 1932.

[3] C. Kennedy, "A Generalisation of the Theory of Induced Bias in Technical Progress," Economic Journal, Vol. 83, No. 329, 1973, pp. 48-57. doi:10.2307/2231099

[4] H. P. Binswanger, "A Microeconomic Approach to Induced Innovation," Economic Journal, Vol. 84, No. 336, 1974, pp. 940-958. doi:10.2307/2230575

[5] D. Acemoglu, "Directed Technical Change," Review of Economic Studies, Vol. 69, No. 4, 2002, pp. 781-809. doi:10.1111/1467-937X.00226

[6] P. Samuelson, "Foundations of Economic Analysis," Harvard University Press, Cambridge, 1947.

[7] P. Samuelson, "An Extension of the LeChatelier Principle," Econometrica, Vol. 28, No. 2, 1960, pp. 368-379. doi: $10.2307 / 1907727$

[8] J. P. Neary, "Trade Liberalisation and Shadow Prices in the Presence of Tariffs and Quotas," International Economic Review, Vol. 36, No. 3, 1995, pp. 531-554. doi: $10.2307 / 2527359$

[9] U. Kreickemeier, "The LeChatelier Principle in the Theory of International Trade," Journal of Economics, Vol. 89 , No. 3, 2006, pp. 245-266. doi:10.1007/s00712-006-0202-x

[10] P. Milgrom and J. Roberts, "The LeChatelier Principle," American Economic Review, Vol. 86, No. 1, 1996, pp. 163-169.

[11] K. Roberts, "Rationality and the LeChatelier Principle," Journal of Economic Theory, Vol. 87, No. 2, 1999, pp. 414-428. doi:10.1006/jeth.1999.2544

[12] A. K. Dixit and V. Norman, "Theory of International Trade: A Dual General Equilibrium Approach," Cambridge University Press, London, 1980. doi:10.1017/CBO9780511628627

[13] D. G. Luenberger, "Dual Pareto Efficiency," Journal of Economic Theory, Vol. 62, No. 1, 1994, pp. 70-85. doi:10.1006/jeth.1994.1004

[14] N. Vousden, "The Economics of Trade Protection," Cambridge University Press, New York, 1990. doi:10.1017/CBO9780511571978

[15] A. H. Turunen-Red and A. D. Woodland, "Strict ParetoImproving Multilateral Reforms of Tariffs," Econometrica, Vol. 59, No. 4, 1991, pp. 1127-1172. doi: $10.2307 / 2938177$

[16] A. H. Turunen-Red and A. D. Woodland, "Multilateral Policy Reforms and Quantity Restrictions on Trade," Journal of International Economics, Vol. 52, No. 1, 2000, pp. 173-148. doi:10.1016/S0022-1996(99)00025-2

[17] M. J. Melitz, "The Impact of Trade on Intra-Industry 
Reallocations and Aggregate Industry Productivity," Econometrica, Vol. 71, No. 6, 2003, pp. 1695-1725. doi:10.1111/1468-0262.00467

[18] J. E. Anderson, G. J. Bannister and J. P. Neary, "Domestic Distortions and International Trade," International Economic Review, Vol. 36, No. 1, 1995, pp. 139-157. doi: $10.2307 / 2527430$

[19] R. C. Feenstra, "Estimating the Effects of Trade Policy," In: G. Grossman and K. Rogoff, Eds., Handbook of International Economics, Elsevier Science, Vol. 3, 1995, pp. 1553-1595.

[20] J. E. Anderson and J. P. Neary, "A New Approach to Evaluating Trade Policy," Review of Economic Studies, Vol. 63, No. 1, 1996, pp. 107-125. doi:10.2307/2298117

[21] J. E. Anderson and J. P. Neary, "The Mercantilist Index of Trade Policy," International Economic Review, Vol. 44, No. 2, 2003, pp. 627-649. doi:10.1111/1468-2354.t01-1-00083
[22] N. H. Chau, R. Fare and S. Grosskopf, "Trade Restrictiveness and Efficiency," International Economic Review, Vol. 44, No. 3, 2003, pp. 1079-1095. doi:10.1111/1468-2354.t01-1-00101

[23] M. Allais, "Traité d'Economie Pure," Vol. 3, Imprimerie Nationale, Paris, 1943.

[24] M. Allais, "La Théorie Générale des Surplus," Economies et Sociétés, Institut des Sciences Mathématiques et Economiques Appliquées, 1981.

[25] D. G. Luenberger, "Microeconomic Theory," McGrawHill, Inc., New York, 1995.

[26] D. G. Luenberger, "Benefit Functions and Duality," Journal of Mathematical Economics, Vol. 21, No. 5, 1992, pp. 461-481. doi:10.1016/0304-4068(92)90035-6

[27] R. T. Rockafellar, "Convex Analysis," Princeton University Press, Princeton, 1996.

[28] A. Takayama, "Mathematical Economics," 2nd Edition, Cambridge University Press, Cambridge, 1985. 


\section{Appendix}

Proof of Lemma 1: Note that $\pi_{j}\left(\mathbf{p}, Y_{j}\right)$ in (1) is convex in $\mathbf{p}$ on $\mathfrak{R}_{+}^{\mathrm{K}}$, and that $\mathrm{e}_{\mathrm{i}}\left(\mathbf{p}, \mathrm{U}_{\mathrm{i}}\right)$ in (4) is concave in $\mathbf{p}$ on $\mathfrak{R}_{+}^{\mathrm{K}}$. Thus, the minimization problem (6) is a convex programming problem. Luenberger [26] defined the benefit function as $\mathrm{b}_{\mathrm{i}}\left(\mathbf{x}_{\mathrm{i}}, \mathrm{U}_{\mathrm{i}}\right) \equiv \max _{\beta}\left\{\beta\right.$ : $\mathrm{u}_{\mathrm{i}}\left(\mathbf{x}_{\mathrm{i}}-\beta \mathbf{g}\right) \geq \mathrm{U}_{\mathrm{i}},\left(\mathbf{x}_{\mathrm{i}}-\beta\right.$ g) $\left.\in \mathfrak{R}_{+}^{\mathrm{K}}\right\}$. The benefit function $\mathrm{b}_{\mathrm{i}}\left(\mathbf{x}_{\mathrm{i}}, \mathrm{U}_{\mathrm{i}}\right)$ is a welfare measure giving the number of units of the reference bundle $\mathbf{g}$ the $\mathrm{i}$-th consumer is willing to give up starting at point $\mathbf{x}_{\mathrm{i}}$ to reach utility $\mathrm{U}_{\mathrm{i}}$. Under the quasi-concavity of $\mathrm{u}_{\mathrm{i}}\left(\mathbf{x}_{\mathrm{i}}\right)$ on $\mathfrak{R}_{+}^{\mathrm{K}}$, Luenberger [26] showed that $\mathrm{b}_{\mathrm{i}}\left(\mathbf{x}_{\mathrm{i}}, \mathrm{U}_{\mathrm{i}}\right)$ is concave in $\mathbf{x}_{\mathrm{i}}$, non-increasing in $\mathrm{U}_{\mathrm{i}}$, and satisfies $\mathrm{e}_{\mathrm{i}}\left(\mathbf{p}, \mathrm{U}_{\mathrm{i}}\right)$ $=\min _{\mathbf{x i}}\left\{\mathbf{p}^{\mathrm{T}} \mathbf{x}_{\mathrm{i}}-\mathrm{b}_{\mathrm{i}}\left(\mathbf{x}_{\mathrm{i}}, \mathrm{U}_{\mathrm{i}}\right): \mathbf{p}^{\mathrm{T}} \mathbf{g}=1, \mathbf{p} \in \mathfrak{R}_{+}^{\mathrm{K}}\right\}, \mathrm{i} \in \mathbf{N}$. Define

$$
\begin{aligned}
& \mathrm{L}(\mathbf{U}, \mathbf{x}, \mathbf{y}, \mathbf{p}, \boldsymbol{\lambda}, \mathbf{t}, \mathbf{q})=\sum_{\mathrm{i} \in N} \mathrm{~b}_{\mathrm{i}}\left(\mathbf{x}_{\mathrm{i}}, \mathrm{U}_{\mathrm{i}}\right) \\
& +\mathbf{p}^{\mathrm{T}}\left[\sum_{\mathrm{i} \in N} \mathbf{w}_{\mathrm{i}}+\sum_{\mathrm{j} \in \boldsymbol{M}} \mathbf{y}_{\mathrm{j}}-\sum_{\mathrm{i} \in N} \mathbf{x}_{\mathrm{i}}\right] \\
& +\boldsymbol{\lambda}^{\mathrm{T}}\left[\sum_{\mathrm{i} \in N \mathrm{~A}} \mathbf{w}_{\mathrm{i}}+\mathbf{q}+\sum_{\mathrm{j} \in \boldsymbol{M A}} \mathbf{y}_{\mathrm{j}}-\sum_{\mathrm{i} \in N \mathrm{~A}} \mathbf{x}_{\mathrm{i}}\right] \\
& +\mathbf{t}^{\mathrm{T}}\left[\sum_{\mathrm{i} \in N \mathrm{~A}} \mathbf{w}_{\mathrm{i}}+\sum_{\mathrm{j} \in \boldsymbol{M A}} \mathbf{y}_{\mathrm{j}}-\sum_{\mathrm{i} \in N \mathrm{~A}} \mathbf{x}_{\mathrm{i}}\right] .
\end{aligned}
$$

Using Equations (1)-(4), $\mathrm{e}_{\mathrm{i}}\left(\mathbf{p}, \mathrm{U}_{\mathrm{i}}\right)=\min _{\mathbf{x i}}\left\{\mathbf{p}^{\mathrm{T}} \mathbf{x}_{\mathrm{i}}-\mathrm{b}_{\mathrm{i}}\left(\mathbf{x}_{\mathrm{i}}\right.\right.$, $\left.\left.\mathrm{U}_{\mathrm{i}}\right): \mathbf{p}^{\mathrm{T}} \mathbf{g}=1, \mathbf{p} \in \mathfrak{R}_{+}^{\mathrm{K}}\right\}$ and assuming that an interior solution to problem (6) exists, it follows from Rockafellar ([27], pp. 281-283) that solving the convex minimization problem (6) is equivalent to finding a saddle-point $\left(\mathbf{x}^{*}, \mathbf{y}^{*}, \mathbf{p}^{*}, \lambda^{*}\right) \in \mathfrak{R}_{+}^{\mathrm{NK}} \times \mathrm{Y} \times \mathfrak{R}_{+}^{\mathrm{K}} \times \mathfrak{R}_{+}^{\mathrm{K}}$ of $\mathrm{L}(\cdot)$ satisfying $\mathbf{p}^{* \mathrm{~T}} \mathbf{g}=1$, where

$$
\begin{aligned}
& \mathrm{L}\left(\mathbf{U}, \mathbf{x}, \mathbf{y}, \mathbf{p}^{*}, \lambda^{*}, \mathbf{t}, \mathbf{q}\right) \\
& \leq \mathrm{L}\left(\mathbf{U}, \mathbf{x}^{*}, \mathbf{y}^{*}, \mathbf{p}^{*}, \lambda^{*}, \mathbf{t}, \mathbf{q}\right) \\
& \quad \leq \mathrm{L}\left(\mathbf{U}, \mathbf{x}^{*}, \mathbf{y}^{*}, \mathbf{p}, \lambda, \mathbf{t}, \mathbf{q}\right),
\end{aligned}
$$

for all $(\mathbf{x}, \mathbf{y}, \mathbf{p}, \boldsymbol{\lambda}) \in \mathfrak{R}_{+}^{\mathrm{NK}} \times \mathrm{Y} \times \mathfrak{R}_{+}^{\mathrm{K}} \times \mathfrak{R}_{+}^{\mathrm{K}}$ satisfying $\mathbf{p}^{\mathrm{T}} \mathbf{g}=1$, and where $\mathrm{V}(\mathbf{U}, \mathbf{t}, \mathbf{q}, \mathrm{Y})=\mathrm{L}\left(\mathbf{U}, \mathbf{x}^{*}, \mathbf{y}^{*}, \mathbf{p}^{*}, \lambda^{*}, \mathbf{t}\right.$, q). Interpret $\mathbf{p}^{*}$ and $\lambda^{*}$ as Lagrange multipliers measuring the shadow prices of the constraints $\left[\sum_{\mathrm{i} \in N} \mathbf{w}_{\mathrm{i}}+\sum_{\mathrm{j} \in \boldsymbol{M}} \mathbf{y}_{\mathrm{j}}-\right.$ $\left.\sum_{\mathrm{i} \in N} \mathbf{x}_{\mathrm{i}}\right] \geq 0$ and $\left[\sum_{\mathrm{i} \in N \mathrm{~A}} \mathbf{w}_{\mathrm{i}}+\mathbf{q}+\sum_{\mathrm{j} \in \boldsymbol{M A}} \mathbf{y}_{\mathrm{j}}-\sum_{\mathrm{i} \in N \mathrm{~A}} \mathbf{x}_{\mathrm{i}}\right] \geq 0$, respectively. Under the normalization rule $\mathbf{p}^{\mathrm{T}} \mathbf{g}=1$, this identifies $\mathbf{p}^{*}$ as the market-clearing prices for the $K$ goods, and $\lambda^{*}$ as the unit quota rents associated with the import quota restriction (5). From the saddle-point theorem ([28], p. 74), (A2) implies the following dual problem

$$
\begin{aligned}
& \mathrm{V}(\mathbf{U}, \mathbf{t}, \mathbf{q}, \mathrm{Y}) \\
& =\operatorname{Max}_{\mathbf{x}, \mathbf{y}}\left\{\sum_{\mathrm{i} \in N} \mathrm{~b}_{\mathrm{i}}\left(\mathbf{x}_{\mathrm{i}}, \mathrm{U}_{\mathrm{i}}\right)\right. \\
& +\mathbf{t}^{\mathrm{T}}\left[\sum_{\mathrm{i} \in N \mathrm{~A}} \mathbf{w}_{\mathrm{i}}+\sum_{\mathrm{j} \in \boldsymbol{M A}} \mathbf{y}_{\mathrm{j}}-\sum_{\mathrm{i} \in N \mathrm{~A}} \mathbf{x}_{\mathrm{i}}\right]: \\
& \sum_{\mathrm{i} \in N} \mathbf{w}_{\mathrm{i}}+\sum_{\mathrm{j} \in \boldsymbol{M}} \mathbf{y}_{\mathrm{j}}-\sum_{\mathrm{i} \in N} \mathbf{x}_{\mathrm{i}} \geq 0, \\
& \sum_{\mathrm{i} \in N \mathrm{~A}} \mathbf{w}_{\mathrm{i}}+\mathbf{q}+\sum_{\mathrm{j} \in \boldsymbol{M A}} \mathbf{y}_{\mathrm{j}}-\sum_{\mathrm{i} \in N \mathrm{~A}} \mathbf{x}_{\mathrm{i}} \geq 0, \\
& \left.\mathbf{x} \in \mathfrak{R}_{+}^{\mathrm{NK}}, \mathbf{y} \in \mathrm{Y}\right\} .
\end{aligned}
$$

This identifies a feasible allocation satisfying the feasibility constraint (3), the quota constraint (5), $\mathbf{x} \in \mathfrak{R}_{+}^{\mathrm{NK}}$ and $\mathbf{y} \in \mathrm{Y}$. And (A3) satisfies profit maximization in (1) and expenditure minimization in (4). In addition, it follows from Equations (A3) and (7) that $\mathrm{W}(\mathbf{U}, \mathbf{t}, \mathbf{q}, \mathrm{Y})$ measures the largest feasible aggregate benefit $\sum_{i \in N} b_{i}\left(\mathbf{x}_{i}\right.$, $\mathrm{U}_{\mathrm{i}}$ ) under policy instruments $(\mathbf{t}, \mathbf{q})$. And $\mathrm{b}_{\mathrm{i}}\left(\mathbf{x}_{\mathrm{i}}, \mathrm{U}_{\mathrm{i}}\right)$ being non-increasing in $U_{i}$, Equations (A3) and (7) imply that $\mathrm{W}(\mathbf{U}, \mathbf{t}, \mathbf{q}, \mathbf{Y})$ is non-increasing in $\mathbf{U}$. Finally, choosing $\mathbf{U}$ $\in\left\{\mathbf{U}^{\prime}: \mathrm{W}\left(\mathbf{U}^{\prime}, \mathbf{t}, \mathbf{q}, \mathrm{Y}\right)=0\right\}$ implies that $\sum_{\mathrm{i} \in N} \mathrm{~b}_{\mathrm{i}}\left(\mathbf{x}_{\mathrm{i}}, \mathrm{U}_{\mathrm{i}}\right)=$ 0 at the optimum, giving $\mathrm{U}_{\mathrm{i}}=\mathrm{u}_{\mathrm{i}}\left(\mathbf{x}_{\mathrm{i}}\right)$ as the utility level obtained for each $i \in N$.

Proof of Proposition 1: For a given $\mathbf{U}$, let $\left(\mathbf{p}^{\mathrm{o}}, \lambda^{\mathrm{o}}, \mathbf{x}^{\mathrm{o}}, \mathbf{y}^{\mathrm{o}}\right)$ be the solution of the saddle-point problem in (A2) under $(\mathbf{t}, \mathbf{q})$, and (p', $\lambda$ ', $\left.\mathbf{x}^{\prime}, \mathbf{y}^{\prime}\right)$ be its solution under (t', $\left.\mathbf{q}^{\prime}\right)$. The second inequality in (A2) implies that

$$
\mathrm{V}\left(\mathbf{U}, \mathbf{t}^{\prime}, \mathbf{q}^{\prime}, \mathrm{Y}\right) \leq \mathrm{L}\left(\mathbf{U}, \mathbf{x}^{\prime}, \mathbf{y}^{\prime}, \mathbf{p}^{\mathrm{o}}, \lambda^{\circ}, \mathbf{t}^{\prime}, \mathbf{q}^{\prime}\right) .
$$

And the first inequality in (A2) implies

$$
\mathrm{L}\left(\mathbf{U}, \mathbf{x}^{\prime}, \mathbf{y}^{\prime}, \mathbf{p}^{\mathrm{o}}, \lambda^{\mathrm{o}}, \mathbf{t}, \mathbf{q}\right) \leq \mathrm{V}(\mathbf{U}, \mathbf{t}, \mathbf{q}, \mathrm{Y}) .
$$

Adding Equations (A4) and (A5), and using (A1), we obtain

$$
\begin{aligned}
& \mathrm{V}\left(\mathbf{U}, \mathbf{t}^{\prime}, \mathbf{q}^{\prime}, \mathrm{Y}\right)-\mathrm{V}(\mathbf{U}, \mathbf{t}, \mathbf{q}, \mathrm{Y}) \\
& \leq \mathrm{L}\left(\mathbf{U}, \mathbf{x}^{\prime}, \mathbf{y}^{\prime}, \mathbf{p}^{\mathrm{o}}, \boldsymbol{\lambda}^{\mathrm{o}}, \mathbf{t}^{\prime}, \mathbf{q}^{\prime}\right)-\mathrm{L}\left(\mathbf{U}, \mathbf{x}^{\prime}, \mathbf{y}^{\prime}, \mathbf{p}^{\mathrm{o}}, \lambda^{\mathrm{o}}, \mathbf{t}, \mathbf{q}\right), \\
&=\lambda^{\mathrm{oT}}\left[\mathbf{q}^{\prime}-\mathbf{q}\right]+\left[\mathbf{t}^{\prime}-\mathbf{t}\right]^{\mathrm{T}} \sum_{\mathrm{i} \in N \mathrm{~A}} \mathbf{w}_{\mathrm{i}}+\left[\mathbf{t}^{\prime}-\mathbf{t}^{\mathrm{T}} \sum_{\mathrm{j} \in \boldsymbol{M A}} \mathbf{y}_{\mathrm{j}}{ }^{\prime}\right. \\
&-\left[\mathbf{t}^{\prime}-\mathbf{t}\right]^{\mathrm{T}} \sum_{\mathrm{i} \in N \mathrm{~A}} \mathbf{x}_{\mathrm{i}}{ }^{\prime}, \\
&= \lambda^{\mathrm{oT}}\left[\mathbf{q}^{\prime}-\mathbf{q}\right]-\left[\mathbf{t}^{\prime}-\mathbf{t}\right]^{\mathrm{T}} \mathbf{m}_{\mathrm{A}},
\end{aligned}
$$

where $\mathbf{m}_{\mathrm{A}}{ }^{\prime} \equiv \sum_{\mathrm{i} \in N \mathrm{~A}} \mathbf{x}_{\mathrm{i}}{ }^{\prime}-\sum_{\mathrm{i} \in N \mathrm{~A}} \mathbf{w}_{\mathrm{i}}-\sum_{\mathrm{j} \in \boldsymbol{M A}} \mathbf{y}_{\mathrm{j}}{ }^{\prime}$. Using Equation (7), (A6) implies

$$
\begin{aligned}
& \mathrm{W}\left(\mathbf{U}, \mathbf{t}^{\prime} \mathbf{q}^{\prime}, \mathrm{Y}\right)-\mathrm{W}(\mathbf{U}, \mathbf{t}, \mathbf{q}, \mathrm{Y}) \\
& \leq \lambda^{\mathrm{oT}}\left[\mathbf{q}^{\prime}-\mathbf{q}\right] \\
& \left.+\mathbf{t}^{\mathrm{T}}\left[\mathbf{m}_{\mathrm{A}}{ }^{*}\left(\mathbf{U}, \mathbf{t}^{\prime}, \mathbf{q}^{\prime}, \mathrm{Y}\right)\right]-\mathbf{m}_{\mathrm{A}}{ }^{*}(\mathbf{U}, \mathbf{t}, \mathbf{q}, \mathrm{Y})\right] .
\end{aligned}
$$

This gives the second inequality in (8). The first inequality is obtained by switching $(\mathbf{t}, \mathbf{q})$ and $\left(\mathbf{t}^{\prime}, \mathbf{q}^{\prime}\right)$ in Equation (A7) and multiplying by (-1).

Proof of Proposition 2: Note that $\mathrm{Y}^{*}(\mathbf{U}, \mathbf{t}, \mathbf{q}) \in \arg$ $\max _{\mathrm{Y}}\{\mathrm{W}(\mathbf{U}, \mathbf{t}, \mathbf{q}, \mathrm{Y}): \mathrm{Y} \in \mathbf{Y}\}$ implies that

$$
\begin{aligned}
& \mathrm{W}\left(\mathbf{U}, \mathbf{t}^{\prime}, \mathbf{q}^{\prime}, \mathrm{Y}^{*}\left(\mathbf{U}, \mathbf{t}^{\prime}, \mathbf{q}^{\prime}\right)\right) \\
& \geq \mathrm{W}\left(\mathbf{U}, \mathbf{t}^{\prime}, \mathbf{q}^{\prime}, \mathrm{Y}^{*}(\mathbf{U}, \mathbf{t}, \mathbf{q})\right) .
\end{aligned}
$$

It follows that

$$
\mathrm{W}\left(\mathbf{U}, \mathbf{t}, \mathbf{q}, \mathrm{Y}^{\mathrm{L}}\right)=\mathrm{W}\left(\mathbf{U}, \mathbf{t}, \mathbf{q}, \mathrm{Y}^{\mathrm{S}}\right),
$$

and

$$
\mathrm{W}\left(\mathbf{U}, \mathbf{t}^{\prime}, \mathbf{q}^{\prime}, \mathrm{Y}^{\mathrm{L}}\right) \geq \mathrm{W}\left(\mathbf{U}, \mathbf{t}^{\prime}, \mathbf{q}^{\prime}, \mathrm{Y}^{\mathrm{S}}\right),
$$

where $\mathrm{Y}^{\mathrm{S}} \equiv \mathrm{Y}^{*}(\mathbf{U}, \mathbf{t}, \mathbf{q}), \mathrm{Y}^{\mathrm{L}} \equiv \mathrm{Y}^{*}\left(\mathbf{U}, \mathbf{t}^{\prime}, \mathbf{q}^{\prime}\right)$. Subtracting (A9) from (A10) gives the first inequality in (13).

To prove the second inequality in (13), note that Equa- 
tion (8) implies

$$
\begin{aligned}
& \mathrm{W}\left(\mathbf{U}, \mathbf{t}^{\prime} \mathbf{q}^{\prime}, \mathrm{Y}^{\mathrm{L}}\right)-\mathrm{W}\left(\mathbf{U}, \mathbf{t}, \mathbf{q}, \mathrm{Y}^{\mathrm{L}}\right) \\
& \leq \lambda^{*}\left(\mathbf{U}, \mathbf{t}, \mathbf{q}, \mathrm{Y}^{\mathrm{L}}\right)^{\mathrm{T}}\left[\mathbf{q}^{\prime}-\mathbf{q}\right]+\mathbf{t}^{\mathrm{T}}\left[\mathbf{m}_{\mathrm{A}}{ }^{*}\left(\mathbf{U}, \mathbf{t}^{\prime}, \mathbf{q}^{\prime}, \mathrm{Y}^{\mathrm{L}}\right)\right. \\
& \left.\quad-\mathbf{m}_{\mathrm{A}}{ }^{*}\left(\mathbf{U}, \mathbf{t}, \mathbf{q}, \mathrm{Y}^{\mathrm{L}}\right)\right],
\end{aligned}
$$

and

$$
\begin{aligned}
& \lambda^{*}\left(\mathbf{U}, \mathbf{t}^{\prime}, \mathbf{q}^{\prime}, \mathrm{Y}^{\mathrm{S}}\right)^{\mathrm{T}}\left[\mathbf{q}^{\prime}-\mathbf{q}\right]+\mathbf{t}^{, \mathrm{T}}\left[\mathbf{m}_{\mathrm{A}}{ }^{*}\left(\mathbf{U}, \mathbf{t}^{\prime}, \mathbf{q}^{\prime}, \mathrm{Y}^{\mathrm{S}}\right)\right. \\
& \left.\quad-\mathbf{m}_{\mathrm{A}}{ }^{*}\left(\mathbf{U}, \mathbf{t}, \mathbf{q}, \mathrm{Y}^{\mathrm{S}}\right)\right] \\
& \leq \mathrm{W}\left(\mathbf{U}, \mathbf{t}^{\prime} \mathbf{q}^{\prime}, \mathrm{Y}^{\mathrm{S}}\right)-\mathrm{W}\left(\mathbf{U}, \mathbf{t}, \mathbf{q}, \mathrm{Y}^{\mathrm{S}}\right) .
\end{aligned}
$$

Adding these two expressions gives the desired result.

Proof of Proposition 3: Under differentiability, the inequality in (14) follows directly from the first inequality in (13) when $\mathbf{t}^{\prime} \rightarrow \mathbf{t}$ and $\mathbf{q}^{\prime} \rightarrow \mathbf{q}$. To prove the equality in (14), let $\operatorname{Dm}_{t}(\mathbf{U}, \mathbf{t}, \mathbf{q}, Y)$ and $\operatorname{Dm}_{q}(\mathbf{U}, \mathbf{t}, \mathbf{q}, Y)$ denote the derivative of $\mathbf{m}_{\mathrm{A}}{ }^{*}(\mathbf{U}, \mathbf{t}, \mathbf{q}, \mathrm{Y})$ with respect to $\mathbf{t}$ and $\mathbf{q}$, respectively, evaluated at $(\mathbf{U}, \mathbf{t}, \mathbf{q}, \mathrm{Y})$. Applying the mean value theorem to $\mathbf{m}_{\mathrm{A}}{ }^{*}(\mathbf{U}, \mathbf{t}, \mathbf{q}, \mathrm{Y})$ yields: $\mathbf{m}_{\mathrm{A}}{ }^{*}(\mathbf{U}$, $\left.\mathbf{t}^{\prime}, \mathbf{q}^{\prime}, \mathrm{Y}\right)-\mathbf{m}_{\mathrm{A}}{ }^{*}(\mathbf{U}, \mathbf{t}, \mathbf{q}, \mathrm{Y})=\mathrm{Dm}_{\mathrm{t}}\left(\mathbf{U}, \theta \mathbf{t}+(1-\theta) \mathbf{t}^{\prime}, \theta \mathbf{q}\right.$ $\left.+(1-\theta) \mathbf{q}^{\prime}, Y\right)\left[\mathbf{t}^{\prime}-\mathbf{t}\right]+\operatorname{Dm}_{\mathrm{q}}\left(\mathbf{U}, \theta \mathbf{t}+(1-\theta) \mathbf{t}^{\prime}, \theta \mathbf{q}+(1\right.$ $-\theta) \mathbf{q}, Y)\left[\mathbf{q}^{\prime}-\mathbf{q}\right]$, for some $\theta \in[0,1]$. Substituting this result into equation (8) and using the definition of a derivative give

$$
\partial \mathrm{W}(\mathbf{U}, \mathbf{t}, \mathbf{q}, \mathrm{Y}) / \partial \mathbf{t}=\mathbf{t}^{\mathrm{T}}\left[\partial \mathbf{m}_{\mathrm{A}}^{*}(\mathbf{U}, \mathbf{t}, \mathbf{q}, \mathrm{Y}) / \partial \mathbf{t}\right],
$$

when $\mathbf{t}^{\prime} \rightarrow \mathbf{t}$ and $\mathbf{q}^{\prime}=\mathbf{q}$, and

$$
\begin{aligned}
& \partial \mathrm{W}(\mathbf{U}, \mathbf{t}, \mathbf{q}, \mathrm{Y}) / \partial \mathbf{q}=\lambda^{*}(\mathbf{U}, \mathbf{t}, \mathbf{q}, \mathrm{Y})^{\mathrm{T}} \\
& +\mathbf{t}^{\mathrm{T}}\left[\partial \mathbf{m}_{\mathrm{A}}{ }^{*}(\mathbf{U}, \mathbf{t}, \mathbf{q}, \mathrm{Y}) / \partial \mathbf{q}\right],
\end{aligned}
$$

when $\mathbf{t}^{\prime}=\mathbf{t}$ and $\mathbf{q}^{\prime} \rightarrow \mathbf{q}$. Equations (A11) and (A12) are "envelope-type" results applying locally in the neighborhood of $(\mathbf{t}, \mathbf{q})$. They imply that

$$
\begin{aligned}
& \mathrm{dW}(\mathbf{U}, \mathbf{t}, \mathbf{q}, \mathrm{Y}) \\
& =\mathbf{t}^{\mathrm{T}}\left[\partial \mathbf{m}_{\mathrm{A}}{ }^{*}(\mathbf{U}, \mathbf{t}, \mathbf{q}, \mathrm{Y}) / \partial \mathbf{t}\right] \mathrm{dt} \\
& +\left[\lambda^{*}(\mathbf{U}, \mathbf{t}, \mathbf{q}, \mathrm{Y})^{\mathrm{T}}+\mathbf{t}^{\mathrm{T}}\left(\partial \mathbf{m}_{\mathrm{A}}{ }^{*}(\mathbf{U}, \mathbf{t}, \mathbf{q}, \mathrm{Y}) / \partial \mathbf{q}\right)\right] \mathrm{d} \mathbf{q}, \\
& =\lambda^{*}(\mathbf{U}, \mathbf{t}, \mathbf{q}, \mathrm{Y})^{\mathrm{T}} \mathrm{d} \mathbf{q}+\mathbf{t}^{\mathrm{T}} \mathrm{dm}_{\mathrm{A}}{ }^{*}(\mathbf{U}, \mathbf{t}, \mathbf{q}, \mathrm{Y}), \quad(\mathrm{A}
\end{aligned}
$$

where $\mathrm{d} \mathbf{m}_{\mathrm{A}}{ }^{*}(\mathbf{U}, \mathbf{t}, \mathbf{q}, \mathrm{Y})=\left[\partial \mathbf{m}_{\mathrm{A}}{ }^{*}(\mathbf{U}, \mathbf{t}, \mathbf{q}, \mathrm{Y}) / \partial \mathbf{t}\right] \mathrm{d} \mathbf{t}+$ $\left[\partial \mathbf{m}_{\mathrm{A}}{ }^{*}(\mathbf{U}, \mathbf{t}, \mathbf{q}, \mathrm{Y}) / \partial \mathbf{q}\right] \mathrm{dq}$. Using (A13) gives the equality in Equation (14). 